\title{
Pandemic crises in financial systems: a simulation-model to complement stress- testing frameworks
}

\author{
Julien Idier ${ }^{1}$, Thibaut Piquard ${ }^{2}$ \\ Working Paper \#621
}

January 2017

\begin{abstract}
We propose in this paper a simulation framework of pandemic in financial system composed of banks, asset markets and interbank markets. This framework aims at complementing the usual stress-test strategies that evaluate the impact of shocks on individual balance-sheets without taking into account the interactions between several components of the financial system. We build on the network model of Gourieroux, Heam, and Monfort (2012) for the banking system, adding some asset market channels as in Greenwood, Landier, and Thesmar (2015) and interbank markets characterized by collateralized debt and margin calls. We show that rather small shocks can be amplified and destabilize the entire financial system. In our framework, the fact that the system enters in an adverse situation comes from first round losses amplification triggered by asset depreciation, interbank contraction and bank failures in chain. From our simulations, we explain how the different channels of transmission play a role in weakening the financial system, and measure the extent to which each channel could make banks more vulnerable.
\end{abstract}

Keywords: bank network, systemic risk, contagion, stress-testing.

JEL classification : E52 E44 G12 C58.

\footnotetext{
${ }^{1}$ Financial Stability Directorate - Banque de France e-mail : julien.idier@banque-france.fr

${ }^{2}$ Paris School of Economics and Banque de France e-mail: thibaut.piquard@banque-france.fr 


\section{NON-TECHNICAL SUMMARY ${ }^{3}$}

From a Macroprudential policy perspective, the ambition to add a macroprudential layer in stresstesting strategies is coherent with the ambition not to safeguard and supervise only individual entities, namely banks, but to understand the rising vulnerabilities of the entire financial system. The principle that a micro-regulation of banks and markets was enough to prevent the financial sphere from systemic crises has been wrong since 2008. Many banks could be solvent and liquid in a static approach, but completely insolvent or illiquid in a dynamic approach. Domino effects, partial defaults, asset market devaluation or interbank freeze can strongly impair the whole financial system when all risks are highly correlated. So far, stress-testing approaches have the main limitation to adopt a static approach which has obvious limitations in this regard by ignoring financial contagion.

Financial contagion, in the literature, has recently been considered through market dynamics and/or correlations of asset prices especially in times of crisis. Several papers have developed such systemic risk measures, relying on market data as the SRISK measure of Acharya, Pedersen, Philippon, and Richardson (2010) enriched by Acharya, Engle, and Richardson (2012), the Composite Indicator of Systemic Stress [CISS] from Hollo, Kremer, and Lo Duca (2012), the Granger causality based approach of Billio, Getmansky, Lo, and Pelizzon (2012) or the Marginal Expected Shortfall of Brownlees and Engle (2012).

These models derived indicators of systemic risk in reduced form i.e. they do not structurally explain why distress could propagate in the financial system and are merely market approximation/ perception of contagion risks.

Another strand of literature underlined the importance of networks to understand financial contagion. This was especially highlighted in Allen and Gale (2000), Eisenberg and Noe (2001) or Gouriéroux, Héam and Monfort (2012). These models incorporate some structural features in contagion analysis but are often insulated from other parts of the financial systems as asset markets. Greenwood, Landier, and Thesmar (2015) have made such an attempt by building a framework in which regulatory constraint may force banks to liquidate a part of their portfolio, taking into account the interaction between the balance sheet composition of banks and asset markets. However there is no direct links between banks through the interbank market.

Our paper builds on these different approaches. Our starting point is the bank network inspired by Gouriéroux, Héam, and Monfort (2012). In their framework, the model aims to "distinguish the exogenous and endogenous dependence" drawing on the Merton (1974) balance sheet model to determine the impact of an exogenous shock on a bank network. Bank assets are split into three parts as bank equities, bank debt and other assets named exogenous assets. A credit institution

\footnotetext{
${ }^{3}$ The paper has previously circulated as "Pandemic crises in financial systems and emergency liquidity". We thank participants at the "stress-testing conference" organized by the "systemic Risk Center - London school of Economics", October 2015; participants of the ESRB/ Bank of Finland conference on financial stability, September 2015; participants of the "Journee d'econometrie" organized by University of Paris X, November 2015; participants of the OFR/Cleaveland Fed annual conference on Financial Stability, December 2015; participants of the "IMF QuantM Seminar", March 2016; participants of Paris Risk Forum, March 2016; participants of the Royal Economic Society, March 2016. We especially thank Jean-Edouard Colliard, Ben Craig, Miguel Segoviano, Jean-Cyprien Ham and Aytek Malkhozov for very useful discussions.
} 
defaults when its liabilities are superior to its assets meaning the defaulted institution has no more equity. The network converges to the equilibrium once no more default is observed.

Our first input is to add to this framework an interbank market where banks have access to collateralized loans: in addition to cross holding equity, banks are thus exposed to each other on the liability side regarding cross holding of interbank repo contracts. The main issue is that these loans are collateralized and thus, subject to margin calls if the value of the collateral is negatively impacted. It creates additional market contagion, such that all assets that banks have on their trading book could be impacted if they are correlated with assets used as collateral. Moreover, while Greenwood, Landier, and Thesmar (2015) use a diagonal price impact matrix, we introduce asset price correlations such that there is a cross market impact of bank deleveraging dynamics. To sum up, our model takes into account several aspects of contagion: (i) Bank solvency contagion (via cross holding of equity); (ii) Bank liquidity contagion (through collateralized interbank loans and margin calls); (iii) Fire-sales dynamics leading to market contagion (when banks suffer liquidity shortage).

The advantage of such a framework is to give policy-makers an analysis of sensitivity of the banking system to shocks, that may not have a direct impact on bank balance sheets (for example the impact of shocks in a market on a bank with no market activity) but have second round effects when the shock propagates through some specific banks, particularly contagious ones, giving rise to financial pandemic. Finally, this framework allows us to test for the optimal design of some policy action aimed at neutralizing some channels of transmission in times of distress: we shown that it could be optimal, in order to limit bank distress, to lower margin calls or to take action in such a way that financial assets used for collateral should be characterized by very high market liquidity. 


\section{RÉSUMÉ : CRISES PANDÉMIQUES DANS LES SYSTÈMES FINANCIERS : UN MODÈLE DE SIMULATION}

POUR COMPLÉTER LES TESTS DE RÉSISTANCE

Nous proposons dans cet article un cadre de simulation de pandémie dans le système financier composé de banques, marchés d'actifs et marchés interbancaires. Ce cadre vise à compléter les stratégies de stress-tests habituelles qui évaluent l'impact des chocs sur les bilans individuels des banques sans tenir compte des interactions entre plusieurs composantes du système financier. Nous nous appuyons sur le modèle de réseau de Gouriéroux, Héam et Monfort (2012) pour le système bancaire, en ajoutant des canaux de transmission via les marchés d'actifs à la Greenwood, Landier et Thesmar (2015) et via les marchés interbancaires caractérisés par des emprunts sécurisés soumis à des appels marges. Nous montrons que des chocs assez petits peuvent être amplifiés et déstabiliser l'ensemble du système financier. Dans notre cadre, le fait que le système entre dans une situation défavorable provient de l'amplification des pertes du premier tour déclenchée par la dépréciation des actifs, la contraction interbancaire et les défaillances bancaires en chaîne. À partir de nos simulations, nous expliquons comment les différents canaux de transmission jouent un rôle dans l'affaiblissement du système financier et évaluons dans quelle mesure chaque canal contribue à rendre les banques vulnérables.

Mots-clés : E52 E44 G12 C58. 


\section{Introduction}

"... the assessment of the Governing Council is that we are in a situation now where you have large parts of the euro area in what we call a bad equilibrium..."

"What we have put in place today is an effective backstop to remove tail risks from the euro area"

President Draghi speech, 6 September 2012.

Even though this present citation applies to a specific context of sovereign market disruptions, the notion of "bad equilibrium" and "tail risk" have often been used in policy communication since the 2008 crisis. In this paper, we consider the two concepts not to be fully equivalent as figure 1 shows. While tail risk characterizes single events occurring with low probability, a bad equilibrium is a different situation where the "norm" can be an apocalyptic situation.

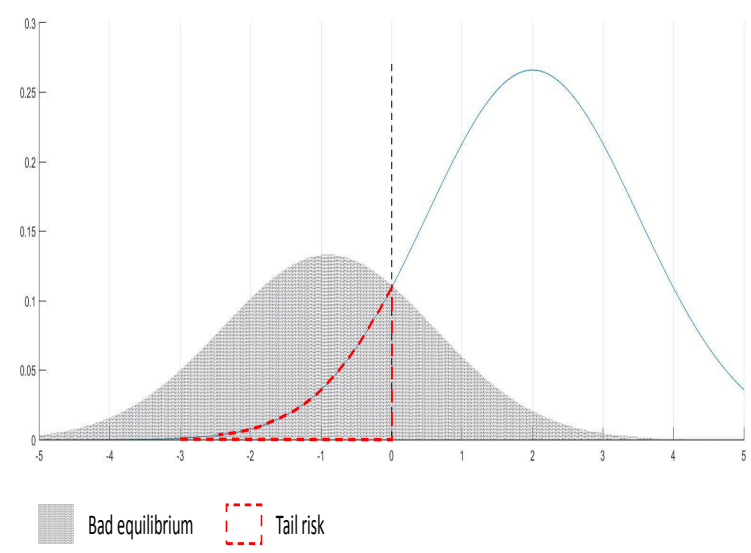

Figure 1: Stylized representation of tail risk and "bad equilibrium".

The rationales for entering in such situation are diverse: self-fulfilling prophecies, dominoes effects, self-reinforcing transmission channels and so on. It differs from tail risk especially with regards to the probability of adverse events, but also regarding the sources of these dynamics. While tail risk appears because of the transmission of a less likely substantial shock, the bad equilibrium is a more dynamic approach, where channels of transmission and amplification are at play. This notion of bad equilibrium could occur when financial networks 
are considered in a dynamic way. While a given shock may affect only one entity, let's say one bank, and have contained consequences, this may not always be the case. For example amplification can lead the system to jump into another configuration giving rise to a "bad equilibrium". The objective of this paper is to illustrate how, drawing on the framework of a network model, such adverse situations can appear dynamically when several transmission channels are at play in the propagation of rather small or idiosyncratic shocks.

Financial contagion, in the literature, was first considered through market dynamics and/or price correlations of asset prices especially in times of crisis as in Adrian and Brunnermeier (2011). In order to draw ex-ante regulation of financial institutions through risk measurement and expected capital shortfall, several systemic risk proxies were developed like the SRISK measure of Acharya, Pedersen, Philippon, and Richardson (2010) enriched by Acharya, Engle, and Richardson (2012). Other measures were constructed such as the Composite Indicator of Systemic Stress [CISS] from Hollo, Kremer, and Lo Duca (2012), the Granger causality based approach of Billio, Getmansky, Lo, and Pelizzon (2012) or the Marginal Expected Shortfall of Brownlees and Engle (2012). Greenwood, Landier, and Thesmar (2015) build on a framework in which regulatory constraint may force banks to liquidate a part of their portfolio. This constraint is violated when a shock hits asset prices. It triggers fire sales because of market's illiquidity. Propagation to other financial institutions occurs when other banks need to deleverage because of the generalized asset prices drop. Price impact of fire sales is linear in the traded amount as presented in particular in Coval and Stafford (2007) and related to the illiquidity measure from Amihud (2002).

The importance of networks to understand financial contagion was first highlighted in Allen and Gale (2000). Eisenberg and Noe (2001) consequently introduced a seminal model of contagion through interbank claims. A bank owns external assets (non-banking ones) and interbank liabilities. Furthermore, part of its liabilities held by other nodes in the network. Equity or net worth is defined as the residual value of assets minus liabilities. Contagion arises when a bank's default may cause other defaults through interbank claims. Indeed, a default decreases the net worth of other nodes as the interbank asset is partially recovered (and is worth less than the initial liability's nominal value). A unique clearing payment vector on reciprocal claims can be derived under reasonable assumptions on the network structure. This framework highlights key vulnerabilities in the network in the sense that highly connected nodes tends to have a larger impact on global resiliency. Many extensions are drawn from this model. Demange (2012) introduces a measure of spillover effects named threat index while Glasserman and Young (2015) show that defaults arising from spillover effects in a framework of interbank claims are less likely than losses attributed to direct shocks on assets. Moreover, Gourieroux, Heam, and Monfort (2012) add to this framework interbank equity cross-holding and derive a unique default equilibrium. Some recent work also focused on the analysis of bank network stability and network stress-testing through solvency or liquidity issues as in Gabrieli, Salakhova, and Vuillemey (2015). These approaches take into account the dynamics of networks made up of the key financial market players (as banks) leading to the risk of contagion. Other models of financial contagion added fire sales to the usual cross-liabilities spillover case as in Cifuentes, Ferrucci, and Shin (2005). If assets are marked to market, then a default has a higher probability to trigger contagion because of asset prices depreciation. 
Margin calls are key model ingredients that can trigger failure when market prices drop. Brunnermeier (2009) explains the key effect of margin calls on the failure of Bear Stearns: some of its hedge funds could not meet their margin calls in cash. The collateral was therefore seized and partially liquidated. It increased fears about the bank's solvency as its ability to refinance worsened, leading to its rescue by JP Morgan. The link between financial market dynamics and leverage is also emphasized in Brunnermeier and Pedersen (2009) or Adrian and Shin (2010) through the collateral and market illiquidity channel. In this paper, we try to cement all these bricks in a single model to consider the different channels of shock transmission, and mainly how one channel could reinforce another and destabilize the financial system as a whole.

From a policy perspective, this approach is in line with the macro-prudential policy ambition and agenda to draft regulation to safeguarding the entire financial system and prevent it from systemic risks. The principle that a micro-regulation of banks and markets was enough to prevent the financial sphere from systemic crises has been wrong since 2008. Many banks could be solvent and liquid in a static approach, but completely insolvent or illiquid in a dynamic approach. Domino effects, partial defaults, asset market devaluation or interbank freeze can strongly impair the whole financial system when all risks are highly correlated: the static approach of stress-testing has obvious limitations in this regard.

The nature of interbank lending has changed substantially since 2008. While unsecured lending consisted in standard interbank contracts, their use significantly dropped after the Lehman collapse as presented in ECB (2015). Despite the fact that unconventional monetary policy as carried out by the central bank decreased the need for liquidity funding, the use of secured lending (bilateral or through CCPs in the Euro-zone) rose since 2009. Therefore to model interbank claims as secured agreements between institutions is more realistic. We also add margin calls to the model for two reasons: in order to ensure consistency with secured lending and because it triggered funding difficulties in the last crisis. It also helps us bridge funding ability with market prices variations in a static balance sheet framework. Finally, one cannot neglect the major effect of indirect contagion via asset prices. The sovereign crisis proved, among other issues, that even liquid assets like sovereign bonds could be subject to market illiquidity. We thus believe it is relevant to model fire sales through price impact. We implicitly assume that there are no fully liquid assets (except for cash) that can be sold without a price impact. We consider it is a good trade-off between tractable and reasonable assumptions. All these reasons motivate our contagion framework relying on collateralized interbank loans with margin calls and fire sales. Equity is marked-to-market in order to account for assets' depreciation in line with several contagion models. Interbank equity cross-holdings are accounted at their market value. Indeed, there is no theoretical rationale to rule out equity cross-holdings while we take into account debt cross-holding, even if interbank equity losses seem to play a minor stake in contagion.

Our paper fits within the financial contagion literature. However, it is closer to research studying network dynamics rather than asset prices. Indeed, we only use results from market contagion to enrich our network model. This adds value to the literature as it offers a comprehensive framework in which several effects are taken into account. This is, to our knowledge, the first model to jointly include fire sales resulting from market illiquidity and 
collateralized debt agreements along with margin calls. This paper presents only the general framework and early results but it could carry substantial policy implications in offering a new way to study contagion in a fully-fledged framework.

Our starting point is the bank network inspired by Gourieroux, Heam, and Monfort (2012). In their framework, the model aims to "distinguish the exogenous and endogenous dependence" drawing on the Merton (1974) balance sheet model to determine the impact of an exogenous shock on a bank network. Bank assets are split into three parts as bank equities, bank debt and other assets named exogenous assets. A credit institution defaults when its liabilities are superior to its assets meaning the defaulted institution has no more equity. The network converges to the equilibrium once no more default is observed. Our first input is to add to this framework an interbank market where banks have access to collateralized loans: in addition to cross holding equity, banks are thus exposed to each other on the liability side regarding cross holding of interbank repo contracts. The main issue is that these loans are collateralized and thus, subject to margin calls if the value of the collateral is negatively impacted. It creates additional market contagion, such that all assets that banks have on their trading book could be impacted if they are correlated with assets used as collateral. As in Greenwood, Landier, and Thesmar (2015), our model considers deleveraging with the main difference that banks must reduce their exposures in order to retrieve liquidity, prompting a price discount in our framework while in Greenwood, Landier, and Thesmar (2015) the deleveraging is triggered by regulatory compliance. Moreover, while Greenwood, Landier, and Thesmar (2015) use a diagonal price impact matrix, we introduce asset price correlations such that there is a cross market impact of deleveraging dynamics. We especially distinguish asset prices correlation in normal times from correlation during crises as outline in Forbes and Rigobon (2001).

To sum up, our model takes into account several aspects of contagion:

- Bank solvency contagion (via cross holding of equity);

- Bank liquidity contagion (through collateralized interbank loans and margin calls);

- Fire-sales dynamics leading to market contagion (when banks suffer liquidity shortage).

Finally, our model may be used to rank banks from the most to the less systemic, taking into account the speed of pandemic propagation. This systemic contagion probability has the advantage to measure the joint effects of direct losses, firesales and margins calls for the entire system triggered by the distress of individual banks.

The paper is organized as follows. In Section 2, we present a Mickey Mouse model with two or three banks to explain the main steps behind the model and the several contagion channels at play. In section 3 , the general model is presented and the properties of the model are discussed. In Section 4, we explain how we retrieve the needed balance sheet data to run the model on public information. Section 5 provides dynamic simulations of our network model and draw a first policy oriented result to assess how systemic a bank may be. Section 6 presents comparative statics and disentangles the various channels of contagion. It also raises the issue of market illiquidity and haircut impact on contagion. 


\section{A simplified version of a contagion model}

Two simplified versions of the general model introduced in this paper are first discussed, providing a general understanding of mechanisms at stake. A two banks universe highlights banks default and liquidation processes. The three banks model then characterizes the interplay between assets prices depreciation and margin calls on secured debt.

\subsection{A two banks universe}

Consider two banks indexed by $i \in\{1,2\}$. On the asset side, each bank $i$ owns $\bar{k}$ assets in quantities $X_{i}$. These are called exogenous assets because they refer to assets that do not belong to the banking system (e.g. non-banking securities, credit to households,...). $P$ contains the $\bar{k}$ prices of these $\bar{k}$ assets. $\bar{k}^{\text {th }}$ asset corresponds to cash and cash equivalent items. Each bank $i$ holds equity from the other institution and itself. On the liability side, we split it into interbank liability $L_{i}^{I}$ and liability to other economic agents such as deposits from customers, $L_{i}^{*}$. Finally, each bank owns a fraction of the other bank's debt. Matrix $\Gamma$ characterizes interbank debt cross-holdings. Table 1 describes balance sheet structures for both banks.

\begin{tabular}{c|cc|c} 
Assets 1 & Liabilities 1 & Assets 2 & Liabilities 2 \\
\hline$\Pi_{1,1} Y_{1}+\Pi_{1,2} Y_{2}$ & $L_{1}^{I}$ & $\Pi_{2,2} Y_{2}+\Pi_{2,1} Y_{1}$ & $L_{2}^{I}$ \\
$\Gamma_{1,2} L_{2}^{I}$ & $L_{1}^{*}$ & $\Gamma_{2,1} L_{1}^{I}$ & $L_{2}^{*}$ \\
$X_{1} P$ & & $X_{2} P$ & \\
\hline$A_{1}$ & $L_{1}$ & $A_{2}$ & $L_{2}$
\end{tabular}

Table 1: Credit institutions 1 and 2 balance sheets

Equity is defined as the residual between assets and liabilities, in line with Merton (1974). Matrices of equity and interbank debt cross-holdings ( $\Pi$ and $\Gamma$ ) must fulfill two constraints: the sum of their terms must be smaller than 1 for a given column, and $\Gamma$ has a null diagonal because a given bank cannot own its debt. Note $\Pi_{i, j}$ (respectively $\Gamma_{i, j}$ ) equity (resp. debt) holdings of bank $i$ in bank $j$.

Consider a given financial shock on the price of exogenous assets such that they are worth $P^{\prime}<P$. This shock is sufficiently high to trigger bank's 1 bankruptcy because the amount of its total liability $L_{1}=L_{1}^{I}+L_{1}^{*}$ exceeds its assets $A_{1}^{\prime}$ after the shock.

The liquidation process follows two steps.

- Step 1: as a direct impact, the fall of exogenous assets prices decreases bank's equity values. In addition, bank's 2 equity is impacted by a decrease in cross-holding equity, because of bank's 1 failure. 
- Step 2: In case of default of bank 1, bank 2 recovers part of bank 1 liability holdings, through collateral, in various assets. Bank 2 recovers $\Gamma(2,1) L_{1}^{I} \frac{\mathbb{1}_{\bar{k}-1}}{k-1}$, considering that collateral is split equally across different $\bar{k}-1$ assets (excluding cash). Exposure matrix is thus updated to $X_{2} P^{\prime}+\Gamma(2,1) L_{1}^{I} \frac{\mathbb{1}_{\bar{k}-1}}{k-1}=X_{2}^{\prime} P^{\prime}$. In addition, we delete debt-holding of bank 1 from bank 2 balance sheet. Table 2 provides the state of the system after bank 1 default.

\begin{tabular}{c|cc|c} 
Assets 1 & Liabilities 1 & Assets 2 & Liabilities 2 \\
\hline$\Pi_{1,1} Y_{1}^{\prime}+\Pi_{1,2} Y_{2}$ & $L_{1}^{I}$ & $\Pi_{2,2} Y_{2}+\Pi_{2,1} Y_{1}$ & $L_{2}^{I}$ \\
$\Gamma_{1,2} L_{2}^{I}$ & $L_{1}^{*}$ & $\Gamma_{2,1} L_{1}^{I}$ & $L_{2}^{*}$ \\
$X_{1} P X_{1} P^{\prime}-\Gamma(2,1) L_{1}^{I} \frac{\mathbb{1}_{\bar{k}-1}}{k-1}$ & & $X_{2} P_{X_{2}} P^{\prime}+\Gamma(2,1) L_{1}^{I} \frac{\mathbb{1}_{\bar{k}-1}}{k-1}=X_{2}^{\prime} P^{\prime}$ & \\
\hline$A_{1}^{\prime}$ & $L_{1}$ & $A_{2}^{\prime}$ & $L_{2}$
\end{tabular}

Table 2: Banks 1 and 2 balance sheets after bank 1 default

Finally, bank 1 exogenous assets are liquidated on the market to recover liability $L_{1}^{*}$. They are sold at a discount given a price impact of trade because the market depth is finite. Exogenous assets new prices become $P^{\prime \prime}<P^{\prime}$. Table 3 presents the two banks balance sheets after bank 1 assets liquidation has led to this additional depreciation.

\begin{tabular}{|c|c|c|c|}
\hline Assets 1 & Liabilities 1 & Assets 2 & Liabilities 2 \\
\hline$\Pi_{1,1} Y_{1}+\Pi_{1,2} Y_{2}$ & $I_{1}^{X}$ & $\Pi_{2,2} Y_{2}+\Pi_{2,1} Y_{1}$ & $L_{2}^{I}$ \\
\hline$\Gamma_{\gamma, 2} L_{2}^{I}$ & $L_{1}^{*}$ & $\Gamma_{2,1} \leftarrow_{1}^{\top}$ & $L_{2}^{*}$ \\
\hline$X_{1} P^{\prime \prime}-\Gamma(2,1) L_{1}^{I} \frac{\mathbb{1}_{\bar{k}}}{k-1}$ & & $X_{2}^{\prime} P^{\prime \prime}$ & \\
\hline$A_{1}^{\prime \prime \prime}$ & $\not / 1$ & $A_{2}^{\prime \prime}$ & $L_{2}$ \\
\hline
\end{tabular}

Table 3: Credit institutions 1 and 2 balance sheets after 1 liquidation

To summarize, if the asset price shock has a direct impact, there is also an indirect impact of bank 1 default through three contagion channels. The first one is the loss of equity cross holding. The second one comes from asset price contagion caused by bank 1 liquidation. The following equation presents equity vector at the end of the scenario.

$$
\left\{\begin{array}{c}
Y_{1}=0 \\
Y_{2}=\frac{1}{\Pi_{2,2}}\left(X_{2}^{\prime} P^{\prime \prime}-L_{2}^{I}-L_{2}^{*}\right)
\end{array}\right.
$$

Bank 2 fails if its equity falls below zero. 


\section{$2.2 \quad$ A three banks universe}

We now complement the default mechanism enriching the dynamics of the interbank market. We especially complement it with margin calls mechanisms when at least two banks survive the default of a third one. Let us consider three banks indexed by $i \in\{1,2,3\}$. Each balance sheet is initially similar to the two banks model.

\begin{tabular}{c|c} 
Assets $i$ & Liabilities $i$ \\
\hline$\Pi_{i, 1} Y_{1}+\Pi_{i, 2} Y_{2}+\Pi_{i, 3} Y_{3}$ & $L_{i}^{I}$ \\
$\Gamma_{i, 1} L_{1}^{I}+\Gamma_{i, 2} L_{2}^{I}+\Gamma_{i, 3} L_{3}^{I}$ & $L_{i}^{*}$ \\
$X_{i} P$ & \\
\hline$A_{i}$ & $L_{i}$
\end{tabular}

Table 4: Bank $i$ balance sheet

Suppose bank 3 fails, right after a the initial shock on asset prices $P^{\prime}<P$. Tables 5 and 6 present the state of the system for defaulted and surviving banks.

\begin{tabular}{c|cc|c} 
Assets 1 & Liabilities 1 & Assets 2 & Liabilities 2 \\
\hline$\Pi_{1,1} Y_{1}+\Pi_{1,2} Y_{2}+\prod_{Y, 3} Y_{3}$ & $L_{1}^{I}$ & $\Pi_{2,1} Y_{1}+\Pi_{2,2} Y_{2}+\prod_{2,3} Y_{3}$ & $L_{2}^{I}$ \\
$\Gamma_{1,2} L_{2}^{I}+\Gamma_{1,3} L_{3}^{I}$ & $L_{1}^{*}$ & $\Gamma_{2,1} L_{1}^{I}+\Gamma_{2,3} L_{3}^{I}$ & $L_{2}^{*}$ \\
$X_{1} P X_{1} P^{\prime}+\Gamma(1,3) L_{3}^{I} \frac{\mathbb{1}_{\bar{k}-1}}{k-1}$ & & $X_{2} P X_{2} P^{\prime}+\Gamma(2,3) L_{3}^{I} \frac{\mathbb{1}_{\bar{k}-1}}{k-1}$ & \\
\hline$A_{1}^{\prime}$ & $L_{1}$ & $A_{2}^{\prime}$ & $L_{2}$
\end{tabular}

Table 5: Bank 1 and 2 balance sheets after bank 3 default

\begin{tabular}{c|c} 
Assets 3 & Liabilities 3 \\
\hline$\Pi_{3,1} Y_{1}+\Pi_{3,2} Y_{2}+\prod_{3,3} Y_{3}$ & $L_{3}^{I}$ \\
$\Gamma_{3,1} L_{1}^{I}+\Gamma_{3,2} L_{3}^{I}$ & $L_{3}^{*}$ \\
$X_{3} P X_{3} P^{\prime}-(\Gamma(1,3)+\Gamma(2,3)) L_{3}^{I} \frac{\mathbb{1}_{\bar{k}-1}}{\bar{k}-1}$ & \\
\hline$A_{3}^{\prime}$ & $L_{3}$
\end{tabular}

Table 6: Bank 3 balance sheet after its default

Still the liquidation process follows two steps: depreciation of equity to zero and recovery of interbank debt through collateral. Therefore, exposure matrices $X_{1}$ and $X_{2}$ are updated so that: $X_{1}^{\prime} P^{\prime}=X_{1} P^{\prime}+\Gamma(1,3) L_{3}^{I} \frac{\mathbb{1}-1}{k-1}$ and $X_{2}^{\prime} P^{\prime}=X_{2} P^{\prime}+\Gamma(2,3) L_{3}^{I} \frac{1}{k-1}-1$. Likewise the two banks universe, defaulted bank remaining assets are liquidated, which puts prices down to $P^{\prime \prime}$. Balance sheets after liquidation are presented in Table 7 . 


\begin{tabular}{c|cc|c} 
Assets 1 & Liabilities 1 & Assets 2 & Liabilities 2 \\
\hline$\Pi_{1,1} Y_{1}+\Pi_{1,2} Y_{2}+\Pi_{1,3} Y_{3}$ & $L_{1}^{I}$ & $\Pi_{2,1} Y_{1}+\Pi_{2,2} Y_{2}+\Pi_{2,3} Y_{3}$ & $L_{2}^{I}$ \\
$\Gamma_{1,2} L_{2}^{I}+\Gamma_{1,3} L_{3}^{I}$ & $L_{1}^{*}$ & $\Gamma_{2,1} L_{1}^{I}+\Gamma_{2,3} L_{3}^{I}$ & $L_{2}^{*}$ \\
$X_{1}^{\prime} P^{\prime \prime}$ & & $X_{2}^{\prime} P^{\prime \prime}$ & \\
\hline$A_{1}^{\prime \prime}$ & $L_{1}$ & $A_{2}^{\prime \prime}$ & $L_{2}$
\end{tabular}

Table 7: Institutions 1 and 2 balance sheets after liquidation

Yet for surviving banks, collateral has been depreciated further such that remaining interbank debt bears less guarantee. To fill in the gap in collateral value, banks have to satisfy margin calls: they must pay their creditors in cash in order to compensate them for the collateral's loss in value. Because this compensation is done across all banks in the system, this could be a zero-sum game if the price impact would not have been considered. Three cases are at stake:

- A bank receives cash from other institutions if it has a positive net position.

- Its cash position decreases if it has a net negative position but enough cash to pay the compensation.

- The bank has to sell part of its assets in order to fund liquidity if it has not enough cash to pay creditors.

The general dynamic on margin call is deepened in Subsections 3.3 and 3.4.3. Banks 1 and 2 respectively suffer collateral depreciation $\delta(1)=\frac{X_{1}^{\prime} P^{\prime \prime}}{X_{1} P}$ and $\delta(2)=\frac{X_{2} P^{\prime \prime}}{X_{2} P}$. We define the margin call matrix $M c$ :

$$
M c=\left(\begin{array}{cc}
0 & (1-\delta(2)) \Gamma_{c o l}(1,2) L_{2}^{I} \\
(1-\delta(1)) \Gamma_{c o l}(2,1) L_{1}^{I} & 0
\end{array}\right)
$$

The net payment situation of each surviving bank vis-a-vis the rest of the financial system $N$ is a zero-sum diagonal matrix: $N(1)=-N(2)=M c(1,2)-M c(2,1)$. Assume now that bank 1 has a negative net position, id est $N(1)<0$, two different cases are at stake whether bank 1 has enough cash to pay 2 or not. Both exposure matrices are updated if it can provide cash without portfolio liquidation.

$$
\left\{\begin{array}{l}
X_{1}^{\prime \prime}(\bar{k})=X_{1}^{\prime}(\bar{k})+N(1) \\
X_{2}^{\prime \prime}(\bar{k})=X_{2}^{\prime}(\bar{k})+N(2)
\end{array}\right.
$$

The second case occurs when bank 1 has not enough cash to pay the compensation. It is then compelled to sell part of its assets in order to fund new liquidity. So we assume that $X_{1}^{\prime}(\bar{k})+N(1)<0$. Exposure to exogenous assets is then reduced in order to fund liquidity. 


$$
\forall j<\bar{k}, X_{1}^{\prime \prime}(j)=X_{1}^{\prime}(j)\left(1-\frac{X_{1}^{\prime}(\bar{k})+N(1)}{\sum_{k=1}^{\bar{k}-1} X_{1}^{\prime}(k) P^{\prime \prime}(k)}\right)
$$

These assets are sold with a price impact that is borne by bank 2. Prices are worth $P^{\prime \prime \prime}$. Finally, cash positions at the end of the round are

$$
\left\{\begin{array}{c}
X_{1}^{\prime \prime}(\bar{k})=0 \\
X_{2}^{\prime \prime}(\bar{k})=X_{2}^{\prime}(\bar{k})+N(2)-\left(X_{1}^{\prime}-X_{1}^{\prime \prime}\right)\left(P^{\prime \prime}-P^{\prime \prime \prime}\right)
\end{array}\right.
$$

Term $\left(X_{1}^{\prime}-X_{1}^{\prime \prime}\right)\left(P^{\prime \prime}-P^{\prime \prime \prime}\right)$ highlights the price impact on bank 2 cash position. Balance sheets after margin calls are presented in Table 8 (for the third case only). Note that interbank lending does not change even if compensations are paid during the period.

\begin{tabular}{c|cc|c} 
Assets 1 & Liabilities 1 & Assets 2 & Liabilities 2 \\
\hline & & & \\
$\Pi_{1,1} Y_{1}+\Pi_{1,2} Y_{2}+\Pi_{1,3} Y_{3}$ & $L_{1}^{I}$ & $\Pi_{2,1} Y_{1}+\Pi_{2,2} Y_{2}+\Pi_{2,3} Y_{3}$ & $L_{2}^{I}$ \\
$\Gamma_{1,2} L_{2}^{I}+\Gamma_{1,3} L_{3}^{I}$ & $L_{1}^{*}$ & $\Gamma_{2,1} L_{1}^{I}+\Gamma_{2,3} L_{3}^{I}$ & $L_{2}^{*}$ \\
$X_{1}^{\prime \prime} P^{\prime \prime \prime \prime}$ & & $X_{2}^{\prime \prime} P^{\prime \prime \prime}$ & \\
\hline$A_{1}^{\prime \prime \prime}$ & $L_{1}$ & $A_{2}^{\prime \prime \prime}$ & $L_{2}$
\end{tabular}

Table 8: Credit institutions 1 and 2 balance sheets after margin calls

\section{General framework}

We present in this section the general setup of our model, in line with the two and three banks simplified versions presented in the previous section. We describe each component in the system, namely the banking system, the asset market and the interbank market.

By designing such architecture in our model, we introduce several transmission channels when the system is in distress. First, domino effects in bank failures due to equity cross holdings. Second, interbank contagion due to cross lending between banks. Finally, asset market contagion due to the use of assets as collateral in the interbank repo markets, and the need of liquidations (fire-sales) to satisfy margin calls and liquidations of defaulted banks. Figure 2 presents the full process between the several components of our model: market contagion, bank liquidation, interbank lending, margin calls. Note that so far in this framework, there is no bank regulation but it could be easily introduced as a more stringent defaulting device than having negative equity. 


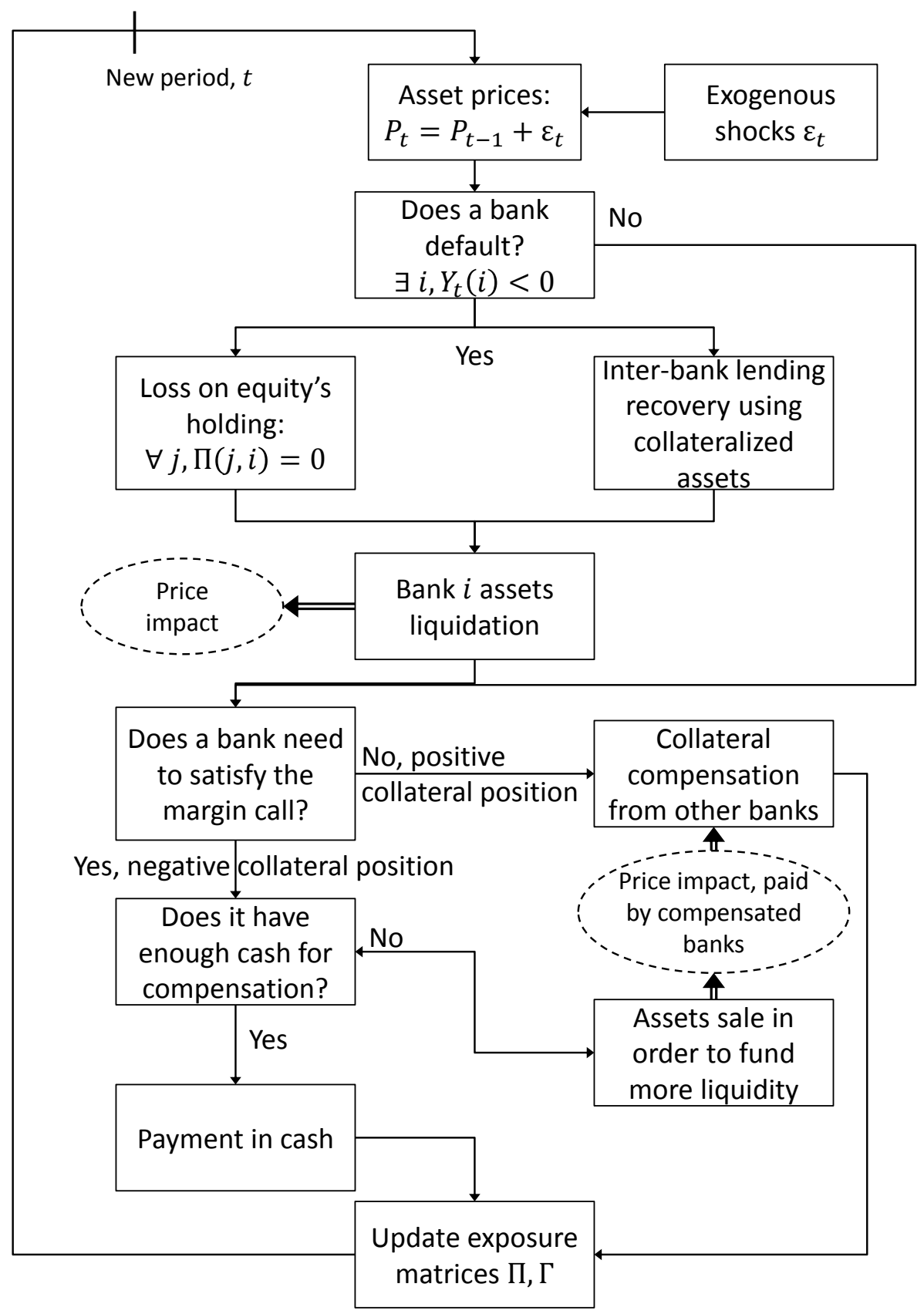

Figure 2: General framework and mechanisms at stake

\subsection{The Banking system}

We follow Merton (1974) and Gourieroux, Heam, and Monfort (2012) model of bank balance sheet, adding interbank lending at the liability side. Let's consider $\mathcal{N}=\llbracket 1, n \rrbracket$ financial institutions (namely banks). They hold a set of $\bar{k}$ exogenous assets, which are not equity or debt from banks modeled in the system. Asset $\bar{k}$ are cash and cash equivalent items. 
Each institution is connected to others through interbank liability and equity cross-holdings. Therefore, asset side is divided into three classes: bank equity, bank liability and exogenous assets. Bank $i$ balance sheet is presented in Table 9 .

\begin{tabular}{c|c} 
Assets $i$ & Liabilities $i$ \\
\hline$\Pi_{i} Y_{t}$ & $L_{i}^{I}$ \\
$\Gamma_{i} L^{I}$ & $L_{i}^{*}$ \\
$X_{i, t} P_{t}$ & \\
\hline$A_{i, t}$ & $L_{i}$
\end{tabular}

Table 9: Bank $i$ balance sheet

with $Y_{t} \in M_{n, 1}(\mathbb{R})$ the vector of equities; $A_{t}$ are assets and $L_{t}$ liabilities, as $n \times 1$ vectors. Liabilities split between interbank lending $L_{i}^{I}$ and other debts $L_{i}^{*}$ such as deposits for example. Both are considered at their nominal value provided bank $i$ does not go bankrupt. We do not differentiate maturities and seniority at the liability side. Banks balance sheet structure remains static over the whole process.

Equity and debt cross-holdings matrices $\Pi$ and $\Gamma$ represent cross exposures between banks in $\mathcal{N} . \Pi_{i, j}$ (respectively $\Gamma_{i, j}$ ) is the share of institution $j$ held by $i$ as a percentage of total equity (respectively liabilities). We assume that $\forall j \in \mathcal{N}, \sum_{i=1}^{n} \prod_{i, j}<1$, ensuring the equity vector admits a fixed point at each period 11 Furthermore, a bank cannot hold its own debt, which means $\Gamma$ has a null diagonal.

Exposure to exogenous assets writes $X_{t} \in M_{n, \bar{k}}(\mathbb{R})$, and corresponding asset prices are $P_{t} \in$ $M_{\bar{k}, 1}(\mathbb{R})$. Matrix $X_{t}$ may have several specifications as it handles elements from the banking book such as loans to non-financial corporate, elements from the trading book (securities, sovereign bonds) and cash. Price changes are driven by market dynamics depending on their liquidity and cross-correlations. In addition, we define in this matrix of exogenous assets, an item called "cash and cash equivalent" as the last column $(\bar{k})$ of $X_{t}$ which always has a null return as we assume there is no inflation and that reserve from central banks are not costly:

$$
X_{t}=\left(\begin{array}{ccc}
\text { Banking book } \text { bank }_{1} & \text { Trading book } \\
\vdots & \vdots & \text { cash }_{\text {bank }} \\
\text { Banking book } & & \vdots \\
\text { bank }_{n} & \text { Trading book } & \\
\text { bank }_{n} & \text { cash }_{\text {bank }}
\end{array}\right)
$$

\subsection{The asset markets}

The model takes into account contagion phenomena in asset markets in two ways:

- Under a price impact hypothesis : when banks need to deleverage or are short in cash, they may need to liquidate assets which triggers loss in asset market value.

\footnotetext{
${ }^{1}$ Data from real interbank equity cross-holding always comply with this assumption.
} 
- Under a market contagion phenomena there is a non-zero correlation matrix between price variations of the liquidated assets and the others. This opens a new wave of contagion that has subsequent impacts on the whole portfolio of the banks.

Adopting this framework means that market contagion is modeled through two channels at each date $t$. First, we consider the price impact Am, similar to Amihud (2002) and second we consider market correlations $R$ such that price impact vector $\psi$ is defined as

$$
\psi=A m R .
$$

$\psi$ is expressed in basis points per unit of traded volume, with $A m$ a $\bar{k} \times \bar{k}$ matrix representing the Amihud statistics for each category of assets and $R$, the $\bar{k} \times \bar{k}$ correlation matrix. In the academic literature, there is extensive literature on asset market correlations as in Masson (1999), Forbes and Rigobon (2001), Karolyi (2003) or Rodriguez (2007). All these papers especially underlined the risk that correlation matrices may be state dependent as soon as a crisis occurs in the system. This could be easily implemented in our framework, considering $R_{s}$ such that correlation increase when a crisis occurs (e.g. $s=1$ when there is at least one default in the system). Then, traded volume must be added in order to estimate the corresponding price impact vector. Here $T V$ is the traded volume in millions such that

$$
\Delta P=T V \psi
$$

During the model dynamics, prices are impacted several times, such that $T V$ depends on the different stages in the process. We divide period $t$ in two subperiods $(t, 1)$ and $(t, 2)$. Between $P_{t, 0}$ and $P_{t, 1}$ the liquidation process triggers asset price variation. Between $P_{t, 1}$ and $P_{t, 2}$, margin calls trigger price variations. At the next round $t+1$, we thus have $P_{t+1,0}=P_{t-1,2}+\epsilon_{t}$ where $\epsilon_{t}$ are Gaussian i.i.d. Figure 3 describes the path of prices along period $t$. A first asset price variations is related to asset liquidation after the shock occurs. Then, the second impact is related to margin calls on the interbank market. 


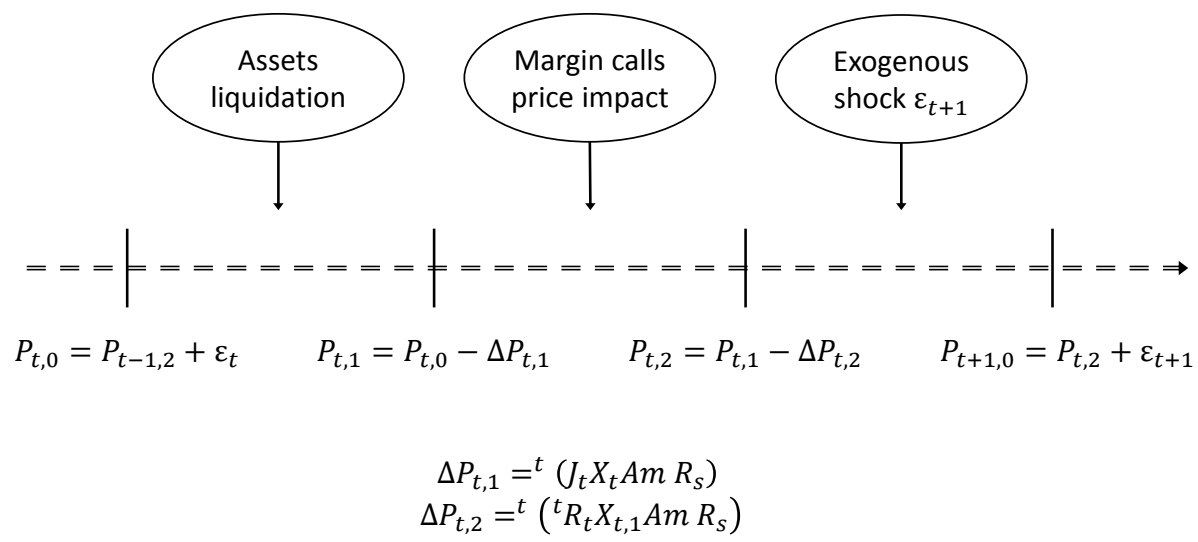

Figure 3: Asset prices variations

\subsection{The interbank market}

In this framework, we introduce an interbank market, through cross-holding of interbank debt. The interbank market is a key element making the bridge between banks' balance sheets and assets markets. Indeed, we assume that all interbank loans are secured for which an amount of collateral needs to guarantee the loan value to protect lenders against default. If exogenous assets immobilized as collateral suffer a negative price shock, the lender asks the debtor to repay in cash part of the loans to maintain the loss given default constant. Two cases unfold. First, the debtor bank repays its margin calls in cash if it has enough treasury to cover margin calls. Second cases arises when the debtor bank has no cash to cover the loss. In this situation, the debtor pays part of the margin call in cash and the remaining part in "assets for liquidation". What we call "assets for liquidation" means that the debtor ex-ante liquidate the necessary volume of assets at date $t$ market price to cover the margin call at the beginning of date $t$ but ex-post, given the price impact of such trade observed at the end of date $t$, the creditor bank may incur an unexpected loss on the margin call proportional to the price impact. These dynamics create negative spirals on the value of the assets and drains liquidity. Note $\delta_{t} \in M_{n, 1}(\mathbb{R})$ the vector that characterizes the depreciation of collateral for each bank.

$$
\delta_{t}=\left(X_{t, 1,\{1, \ldots, \bar{k}-1\}} P_{t, 1,\{1, \ldots, \bar{k}-1\}}\right) \oslash\left(X_{t, 1,\{1, \ldots, \bar{k}-1\}} P_{t-1,2,\{1, \ldots, \bar{k}-1\}}\right)
$$

where $\oslash$ is the Hadamard division. Assuming all exogenous assets are taken as collateral in equal proportions, asset depreciations affect collateral value with a discount. Therefore, we 
define a new matrix $M c$ that is the amount of cash (or margin call) bank $j$ owes to $i$ because of the collateral depreciation. Assuming all interbank debt are secured by collateral with a given haircut, we define a matrix $\Gamma_{c o l}$ whom coefficients are those of $\Gamma$ time the haircut (i.e. the percentage of debt collateralized). This implies that the margin call is:

$$
\forall(i, j) \in \llbracket 1, n \rrbracket^{2}, M c_{t}(i, j)=\left(1-\delta_{t}(j)\right) \Gamma_{c o l}(i, j) L^{I}(j)
$$

Given the margin calls through the entire system of banks, each bank has now a net position at date $t$ :

$$
N_{t}(i)=\sum_{l=1}^{n}\left(M c_{t}(i, l)-M c_{t}(l, i)\right)
$$

In the dynamic process that we detail in Section 3.4, banks finally have to satisfy the constraints by cash or asset transfer.

\subsection{The spread of financial contagion}

\subsubsection{Bank defaults and creditor recovery}

Let considers $\{1, \ldots, T\}$ finite periods and recall bank assets and liabilities are expressed as:

$$
\left\{\begin{array}{c}
A_{t}=\Pi Y_{t}+\Gamma L^{I}+X_{t} P_{t} \\
L=L^{I}+L^{*}
\end{array}\right.
$$

Equity is defined as the residual between assets and liabilities. Without any default, equity writes:

$$
Y_{t}=(I d-\Pi)^{-1}\left((\Gamma-I d) L^{I}-L^{*}+X_{t} P_{t, 0}\right)
$$

In the advent of a default, equity is valued at zero for other banks because of shareholders' limited liability. This model is bound to solvency concerns such that defaults caused by regulatory constraints do not happen in this framework. Merton (1974) definition of equity reflects a double constraint on equity and liability.

$$
\left\{\begin{array}{c}
Y_{i, t}=\left(A_{i, t}-L_{i, t}\right)^{+} \\
L_{i, t}=\min \left(L_{i}^{*}+L_{i}^{I}, A_{i, t}\right)
\end{array}\right.
$$

In case of bankruptcy, collateralized debt-holders get back part of their investment whereas the remaining assets are sold to liquidate other debt $L^{*}$. Bank defaults impact other institutions balance sheets through three channels: equity cross-holdings, interbank loans and assets price depreciations. Consider a given period $t$ in which bank $i \in \llbracket 1, n \rrbracket$ fails. Liquidation process is split in two steps. First, shareholder holdings in the failed bank are worth zero because of debt seniority over equity.

$$
\forall j \in \llbracket 1, n \rrbracket, \Pi(j, i)=0
$$

Second, interbank liability is recovered in two steps: bank debt-holders first get back their collateral from debt $L^{I}$; assets are then liquidated to recover the remaining liability $L^{*}$. 
Creditors recover part of their liability through collateralized assets, not cash. We assume collateral is equally divided among exogenous $\bar{k}-1$ assets for each bank. Therefore, exposure matrix $X_{t}$ changes with debt recovery process from $X_{t}$ to $X_{t, 1}$. We implicitly assume interbank debt-holding cannot be reused as collateral for interbank liabilities. New exposures $X_{t, 1}$ depend on the cross holding of debt $\Gamma$, the interbank liability $L^{I}$ and the number of defaults. Define the dummy vector representing events of bank default $I_{t} \in M_{n, n}(\mathbb{R})$ such that

$$
I_{t}(i, i)=\left\{\begin{array}{l}
0, Y_{i, t}>0 \\
1, Y_{i, t} \leq 0
\end{array}\right.
$$

This diagonal matrix characterizes the set of defaulting banks $\mathrm{I}^{2}$ Exposure matrix is updated such that

$$
X_{t, 1\{1, . ., n\}\{1, . ., \bar{k}-1\}}=X_{t\{1, . ., n\}\{1, . ., \bar{k}-1\}}+I_{t}\left(\Gamma L^{I}-\left(\sum_{l<t} m c_{l}\right) \operatorname{diag}\left(I_{t}\right)-S_{t} L^{I}\right) \frac{\mathbb{1}_{\bar{k}-1}}{\bar{k}-1} \oslash P_{t,\{1, . ., \bar{k}-1\}}
$$

Once interbank debt from the defaulted institution has been recovered, interbank lending to the defaulted bank is null: $\forall j \in\{1, . ., n\}$, st $j \neq i, \Gamma(j, i)=0$. We take into account past margin calls to avoid over-recovery of interbank loans: a bank can recover at most its initial lending from its counterparty. It prevents pathological cases in which some banks benefit from over-collateralized loans.

\subsubsection{Exogenous assets liquidation and market contagion}

Exogenous assets are liquidated on the market in order to provide cash for remaining debtholders $L_{i}^{*}$. However, the market is not deep enough to absorb instantaneously such quantities of assets. Therefore prices are negatively impacted and debt-holders do not get back the initial value of the collateral due to ex-post market impact of fire-sales represented by the price impact vector $\psi$ as defined in subsection 3.2. Note that the last element of $\psi$ is zero because cash is not subject to firesales. With $J_{t}=\operatorname{diag}\left(I_{t}\right)$ the price impact $\Delta P_{t, 1}$ writes

$$
\Delta P_{t, 1}=\left(J_{t} X_{t} \psi\right)^{\prime}
$$

Asset prices are now $P_{t, 1}=P_{t, 0}-\Delta P_{t, 1}$.

\subsubsection{Margin calls on secured interbank lending for surviving banks}

Margin calls and net payments are already computed in subsection 3.3. We differentiate two cases among banks with a negative net payment $\left(N_{t}(i)<0\right)$ depending on whether the bank has enough cash to satisfy margin calls or not and thus must sell part of its assets. Note two indicative vectors $K_{t, 1}$ and $K_{t, 2}$, characterizing whether the net payment of collateral is

\footnotetext{
${ }^{2}$ Note $\mathbb{1}_{\bar{k}-1} \in M_{1, \bar{k}-1}(\mathbb{R})$ a vector filled with 1 and $S_{t}$ a diagonal matrix which reports the share of interbank collateral owned to other players in case of default: $S_{t}(i, i)=\sum_{l=1}^{n}\left(1-I_{t}(l, l)\right) \Gamma_{\text {col }}(l, i)$
} 
positive or not and whether is a bank with a negative net payment has enough cash to stand margin calls.

$$
\begin{gathered}
K_{t, 1}(i)=\left\{\begin{array}{c}
1, N_{t}(i, i)<0 \\
0, \text { otherwise }
\end{array}\right. \\
K_{t, 2}(i)=\left\{\begin{array}{c}
1, N_{t}(i, i)<0, N_{t}(i, i)+X_{t}(i, \bar{k})<0 \\
0, \text { otherwise }
\end{array}\right.
\end{gathered}
$$

Firesales arise for bank $j$ when $K_{t, 2}(j, j)=1$. Therefore, exposure to exogenous assets (except for cash) is reduced for banks that have to sell part of their assets. We define a recovery vector ratio named $\operatorname{Rec}_{t} \in M_{n, 1}(\mathbb{R})$ corresponding to the amount of assets that need to be liquidated as a share of the bank's total exposure (excluding cash).

$$
R e c_{t}=\left(K_{t, 2} \odot\left(N_{t}+X_{t, 1,\{\bar{k}\}}\right)\right) \oslash\left(X_{t, 1,\{1, \ldots, \bar{k}-1\}} P_{t, 1,\{1, \ldots, \bar{k}-1\}}\right)
$$

with $\odot$ the Hadamard product and $\oslash$ the Hadamar division Thus, exposure after payment of margin calls write

$$
\forall k<\bar{k}, \forall i \in\{1, . ., n\}, X_{t, 2}(i, k)=X_{t, 1}(i, k)\left(1-\operatorname{Rec}_{t}(i)\right)
$$

The price impact amounts to $\Delta P_{t, 2}=\left(\operatorname{Rec}_{t}^{\prime} X_{t, 1} \psi\right)^{\prime}$, such that creditors bear the price impact ex-post of asset liquidations. Then cash movements are characterized by

$$
\begin{aligned}
& \forall i \in\{1, . ., n\}, X_{t, 2}(i, \bar{k})=X_{t, 1}(i, \bar{k})+K_{t, 1}(i)\left(1-K_{t, 2}(i)\right) N_{t}(i) \\
& \quad-K_{1, t}(i) K_{2, t}(i) X_{t, 1}(i, \bar{k})+\left(1-K_{t, 1}(i)\right)\left(N_{t}(i)-\frac{{ }^{t} \operatorname{Rec}_{t} X_{t, 1} \Delta P_{t, 2}}{n-\sum_{l=1}^{n} K_{t, 1}(l)}\right)
\end{aligned}
$$

Three cash changes correspond to the three net payment possibilities, id est positive payment, negative payment with a sufficient cash position to pay the bill and negative payment with an insufficient cash position. Positive payment is modeled by $\left(N_{t}(i)-\frac{{ }^{t} R_{t} X_{t, 1} \Delta P_{t, 2}}{n-\sum_{l=1}^{n} K_{t, 1}(l)}\right)$ term. Notice that the price impact is borne by banks having a positive net collateral position. Banks with a negative payment with a sufficient cash position to carry losses are represented by $K_{t, 1}(i)\left(1-K_{t, 2}(i)\right) N_{t}(i)$ whereas credit institutions having to sell non cash assets reduce their cash position to zero: $-K_{1, t}(i) K_{2, t}(i) X_{t, 1}(i, \bar{k})$.

\subsubsection{Conclusion of the round}

Defaulted players have been liquidated in the former steps and have no more links with the rest of the network. Exposures $X$ to exogenous assets have been updated twofold over the period. If banks go bankrupt, they are removed of the universe at the end of the period in which they default. Therefore, exposure matrices must be reduced. If bank $i$ fails, $\Gamma$ and $\Pi$ line's and column's $i$ are removed. Line $i$ is also removed from $X_{t, 2}$ matrix. 


\section{Model Calibration}

We consider a financial system composed by 6 banks, an interbank market characterized by secured lending and a financial asset market. In this paper, we only use approximation of what could be a realistic banking system. In other words, we do not use regulatory information at the disposal of banking supervision authorities but rather consider a realistic but approximated situation of a banking system. All the information needed in this model is easily available, and could be approximated by annual bank statement such that it could be easily implemented.

The simulation thus considers a system of 6 banks characterized by non-zero cross holdings, bilateral trading on the interbank, and for some of them, significant market activities. These 6 banks are different by their size, their business models and the resulting composition of their simplified balance sheets. The below data are purely hypothetical.

\subsection{Equity cross-holdings}

Equity cross-holding matrix is built such that some may have, for example, joint subsidiaries, some may not. The following table gives the structure of such equity cross-holdings in our system.

\begin{tabular}{c|cccccc}
$\Pi(\%)$ & Bank 1 & Bank 2 & Bank 3 & Bank 4 & Bank 5 & Bank 6 \\
\hline Bank 1 & 0.01 & 0 & 0 & 0 & 0 & 0 \\
Bank 2 & 0 & 0 & 0.3 & 0 & 0 & 0 \\
Bank 3 & 0.02 & 0 & 1 & 0 & 0.3 & 1 \\
Bank 4 & 0 & 0 & 1 & 0.1 & 0.4 & 1 \\
Bank 5 & 0 & 0 & 1 & 0 & 0.1 & 1 \\
Bank 6 & 0 & 0 & 1 & 0.2 & 0.2 & 5
\end{tabular}

Table 10: Equity cross-holding matrix $\Pi$

For example, Bank 1 is characterized by no holdings of its own equity by the other banks, such that there is no reason, via the sole cross-equity holding channel, that its default affects the solvency of the other. This is not the case for bank 3 for example, which capital belongs for significant amount to others. This information set belongs to the corporate structure of financial institutions.

\subsection{Bank debt cross-holdings}

Unlike equity, debt cross-holdings are the most difficult piece of information to obtain but are often at the disposal of policy-makers. Some aggregated loans to other credit institutions are presented in public balance sheets, as well as deposit from other banks. From this aggregate several simulation methodologies could be used. How to obtain such matrix by simulation 
network technologies is not the purpose of this paper (see Anand, van Lelyveld, Banai, Friedrich, Garratt, Halaj, Howell, Hansen, Martnez Jaramillo, Lee, Nobili, Rajan, Salakhova, Silva, Silvestri, and Stancato de Souza (2015) for a survey on these methodologies). Here, we assume the following form of interbank exposure matrix. Our matrix describes a situation in which some banks strongly relies on interbank transactions, while some others are more immune to the potential freeze of this market.

\begin{tabular}{c|cccccc}
$\Gamma(\%)$ & Bank 1 & Bank 2 & Bank 3 & Bank 4 & Bank 5 & Bank 6 \\
\hline Bank 1 & 0 & 15 & 15 & 15 & 15 & 15 \\
Bank 2 & 25 & 0 & 20 & 25 & 30 & 25 \\
Bank 3 & 10 & 10 & 0 & 10 & 5 & 10 \\
Bank 4 & 25 & 25 & 25 & 0 & 30 & 25 \\
Bank 5 & 25 & 30 & 25 & 30 & 0 & 25 \\
Bank 6 & 15 & 20 & 15 & 20 & 20 & 0
\end{tabular}

Table 11: Debt cross-holding matrix $\Gamma$

The haircut $h$ is such that $\Gamma_{c o l}=h \odot \Gamma$. We consider over-collateralized debt at $h=1.4$.

\subsection{Balance sheets}

Exposure matrix $X$ is composed of 6 assets: loans to the non-banking sector, debt instruments, equity instruments, derivatives instruments, other securities and cash. This structure of balance sheet could be easily retrieved in annual statement of banks. Finally, remaining liability $L^{*}$ is estimated as the difference between the sum of the portfolio of exogenous assets, the interbank liability and equity, minus the amount of equity: i.e. the remaining part of the balance sheet. Table 12 presents equity and non-banking liability $L^{*}$.

\begin{tabular}{c|c|c} 
Bank & $Y$ & $L^{*}$ \\
\hline Bank 1 & 2,5 & 30,5 \\
Bank 2 & 0,75 & 8,6 \\
Bank 3 & 4,9 & 92 \\
Bank 4 & 5,5 & 78 \\
Bank 5 & 4,4 & 49,5 \\
Bank 6 & 4,9 & 53
\end{tabular}

Table 12: Equity and non-banking liability

The table shows that banks are heterogeneous in terms of size, by factor 5 in equity. Finally, exposure to exogenous assets $X$ is described in Table 13 . 


\begin{tabular}{c|cccccc} 
Bank & loans & debt & equity & derivatives & other securities & cash \\
\hline Bank 1 & 19,5 & 8,5 & 2,5 & 0,5 & 0 & 2 \\
Bank 2 & 3,5 & 2,3 & 0 & 0,1 & 0 & 0,1 \\
Bank 3 & 35 & 28 & 7,5 & 23,5 & 0 & 6 \\
Bank 4 & 39 & 28 & 2,5 & 12,5 & 0 & 3 \\
Bank 5 & 31 & 10 & 3 & 4,5 & 0 & 4 \\
Bank 6 & 17,5 & 11,5 & 6,5 & 12,5 & 7 & 3
\end{tabular}

Table 13: Exposure matrix $X$

This matrix reflects potential differences in business models. Taking loans as an example highlights bank 3 and bank 4 both have a significant loan portfolio in terms of size, but differ given the importance of market activity since bank 3 is much more active in terms of derivatives or "other securities" than bank 4. This heterogeneity will be used to better describe how the different contagion channels impact the different banks depending on the structure of their balance sheets.

\subsection{Asset markets}

The purpose of this simulation is to assess the resilience of the financial system modelled and the emergence of a situation in which the financial system is strongly affected due to selfreinforcing dynamics. We consider an initial shock that hits trading assets by an amount of $7.5 \%$, which is significant but not apocalyptic, since it triggers no default on the first round. To match balance sheet public information trading assets are debt, equity, derivatives and other securities. Trading assets volatility is at $15 \%$ (yearly) whereas the volatility on the loans portfolio is about $2 \%$. Correlation matrices $R_{\text {norm }}$ and $R_{\text {crisis }}$ are obtained by calculating correlations between eurostoxx 50, corporate bonds and iTraxx indexes, considering that these correlations are doubled when a default event occurs. Obviously, cash and cash equivalent are not hit by any shock. We calibrate the Amihud statistics to $0.2 \times 10^{-2}$.

\begin{tabular}{lc} 
Description & Parameter value \\
\hline Initial shock on securities & $7.5 \%$ \\
\hline Securities volatility & $15 \%$ \\
Loans volatility & $2 \%$ \\
\hline Amihud statistics & $2 \times 10^{-3}$
\end{tabular}

Table 14: Calibrated parameters values for asset markets 


\section{Simulation Results}

This section presents results obtained for the network model described in former sections. Every distribution relies on a sample of 100,000 simulations. We first show to what extent contagion effects harm banks solvency, highlighting the need to include second round effects in stress testing frameworks. We are then able to identify the triggers of such contagion and finally discuss the role and detection of systemic banks in this framework.

\subsection{The impact on banks' solvency}

As described in section 4, we start with a shock on trading assets that causes no default in the first period in order to emphasize on second round effects. Figure 4 presents the evolution of conditional probabilities of default. Our first finding shows that contagion effects should not be neglected while estimating solvency through stress testing exercises. In fact, all banks are more sensitive to contagion effects than to the initial shocks.

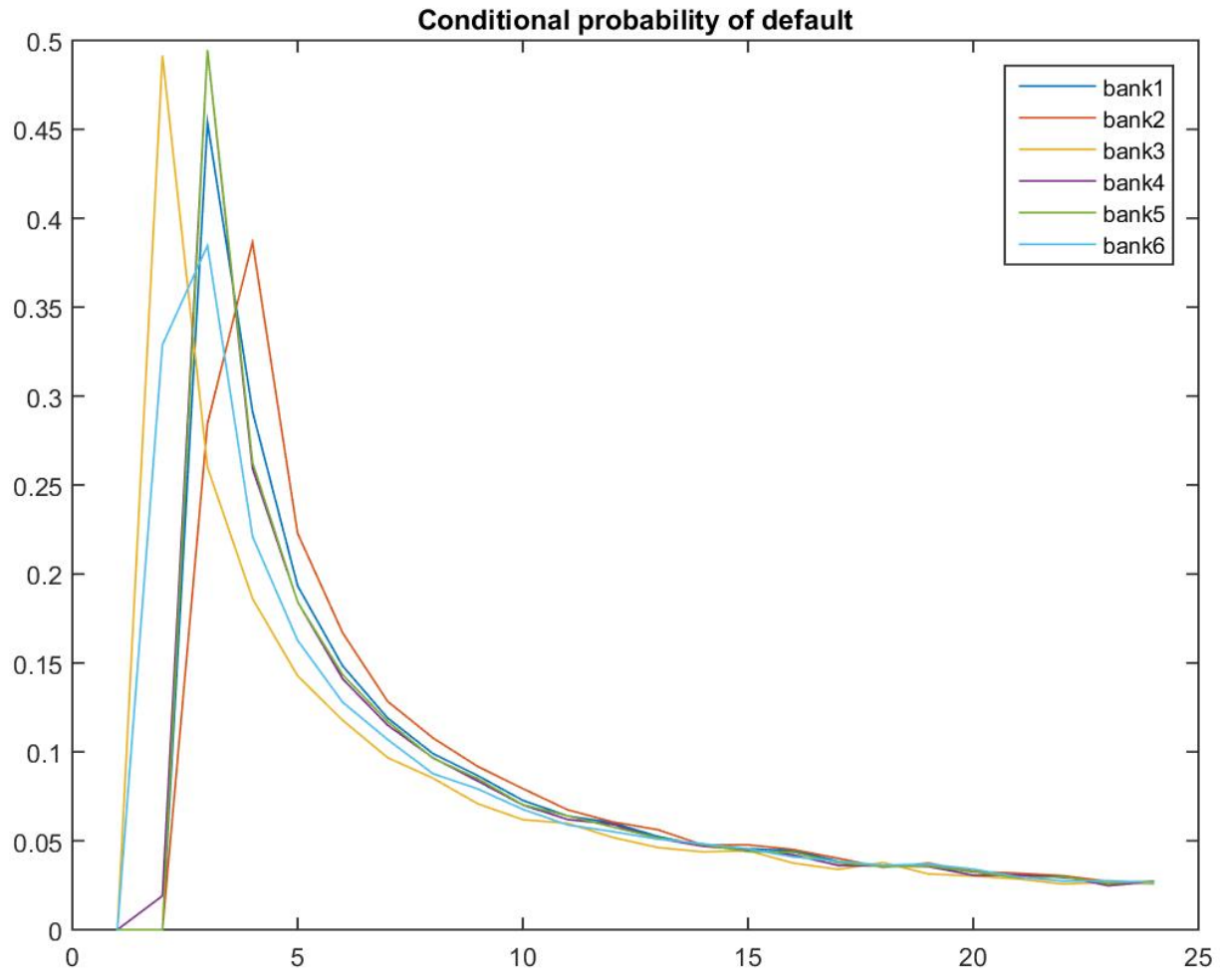

Figure 4: Banks PDs evolution.

Note: PDs for each bank are here obtained as a number of bank defaults at time t across simulations over the number of non defaults of bank $i$ at time $t-1$ 
For a given shock which triggers no default, probabilities of default on subsequent rounds are however higher: around 0.5 for banks relying mostly on trading assets in their balance sheet. The rationale behind this figure is in line with the theory: this shock weakens banks in the first step. As their exposure to exogenous assets are different, margin calls movements worsen the position of fragile banks whereas it improves those of institutions that have not been too much affected by the shock. As a consequence, variations in asset prices at the beginning of next period cause defaults (period 2). Although conditional probabilities of default have the same pattern, id est strictly increasing and then strictly decreasing, maximums are not reached at the same period for all banks. The figure highlights direct contagion effects banks with most exposure to the shock, which fail first, to vulnerable ones which have a small probability of default in period 2 but are more likely to default in the next ones. For example, banks 1, 4 and 2 reach maximum PDs in periods 3 and 4 while they are considered as highly solvent institutions after first round losses in period 1. Less connected institutions such as bank 2 are more resilient to second round effects but fail anyway because of the impact on asset prices. Evolution of conditional probabilities of default thus shows that first round stress testing underestimates the overall impact of a shock if contagion is not taken into account.

Figure 5 presents the full equity loss distribution for each bank in our sample. A key results is that for a rather small shock, the default distribution for each bank tends to be quite complex: we observe in the dynamic of the process that equity distributions are multimodal, especially after 4 rounds. Banks $\{1,2,4,5\}$ are the most obvious cases, while banks $\{3,6\}$ are intermediate cases.

At the first round of losses, all equity distributions are unimodal, such that the risk of default represents the direct impact of the shock. Then, during the subsequent rounds, these risks are altered toward entire distributions shifted to negative values such that it is more likely to default for some banks.

Modes at the left of the distribution characterize amplification phenomena that are not often captured in static models of stress tests, or in dynamic models that do not consider enough transmission channels. Indeed, we underestimate the risk for the financial system as soon as the only criteria to make a financial system collapsing is the size of the initial shock (assigned with a low probability) without considering the interactions that can be much more adverse for the system especially given its probability of occurrence. This multimodality means that endogenous financial loops reinforces shock propagation and banks have to deal with different concomitant risks represented by a mixture of risk distributions.

A key question in terms of network resilience is "why this does not happen to all banks". Considering the initial shocks, affecting asset markets, banks with a relatively high trading book are more affected than others in terms of "direct effects". However, our model shows that the propagation of the shock finally affects all banks (through the loss in equity crossholdings, or interbank lending). Finally, this multimodality does not persist along the process since defaults are less likely at a later stage as soon as the weakest entities have already defaulted. 

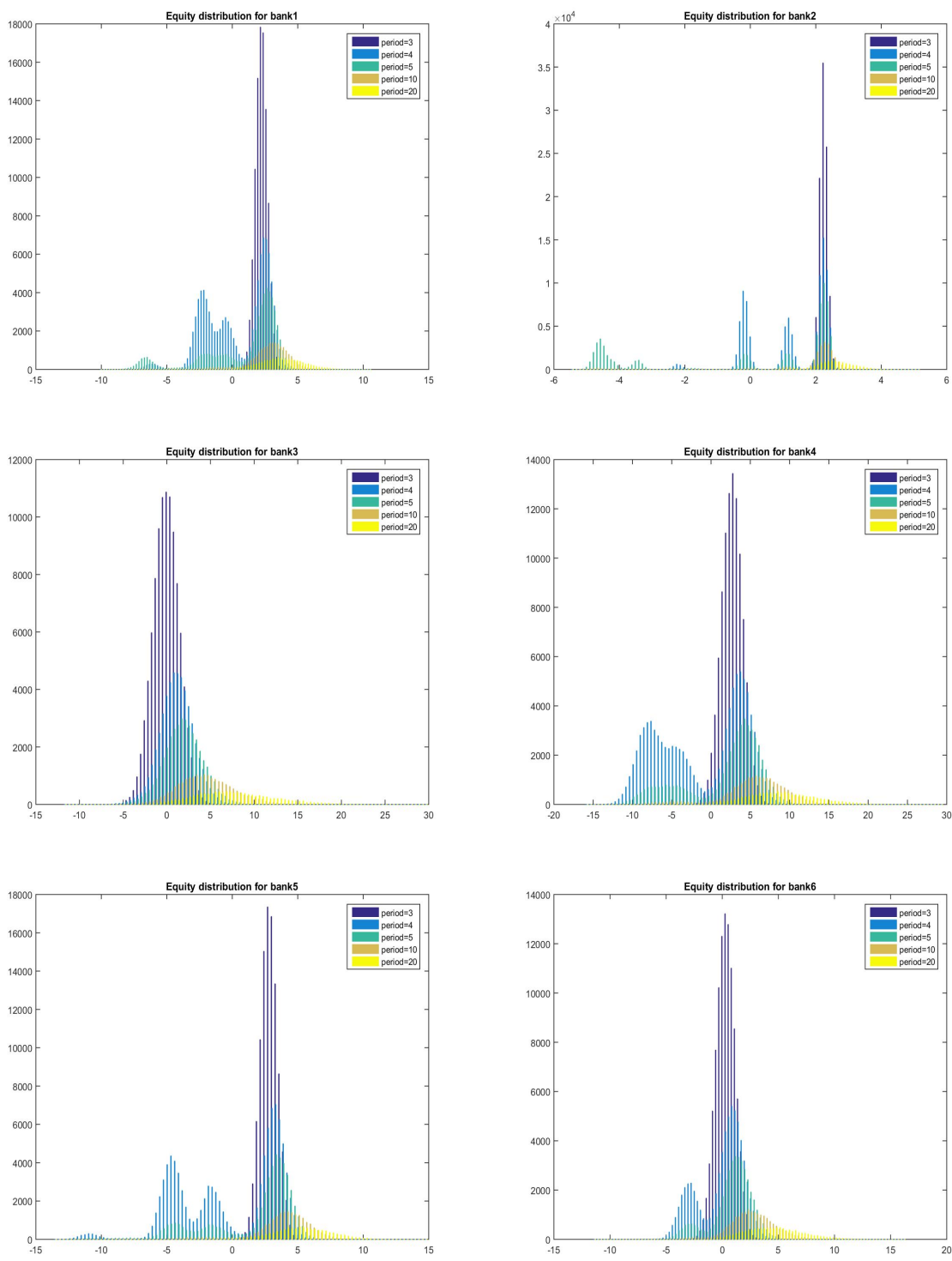

Figure 5: Equity loss distribution obtained from the model's simulation.

Note: Equity loss distribution at periods $\{3,4,5,10,20\}$ for each bank. At date $t$, equity distribution handles banks alive at period $t-1$.

\subsection{Multimodality and domino effects}

Our first results highlight multimodal distributions caused by contagion effects. This subsection takes a closer look to the triggers of such contagion. We split in the simulation equity distributions depending on the number of defaults in the system. Figure 6 presents equity distributions in period 3. This period coincides with the start of the contagion: first defaults occur in period 2 because no direct default occur following the initial shock in period 1. 

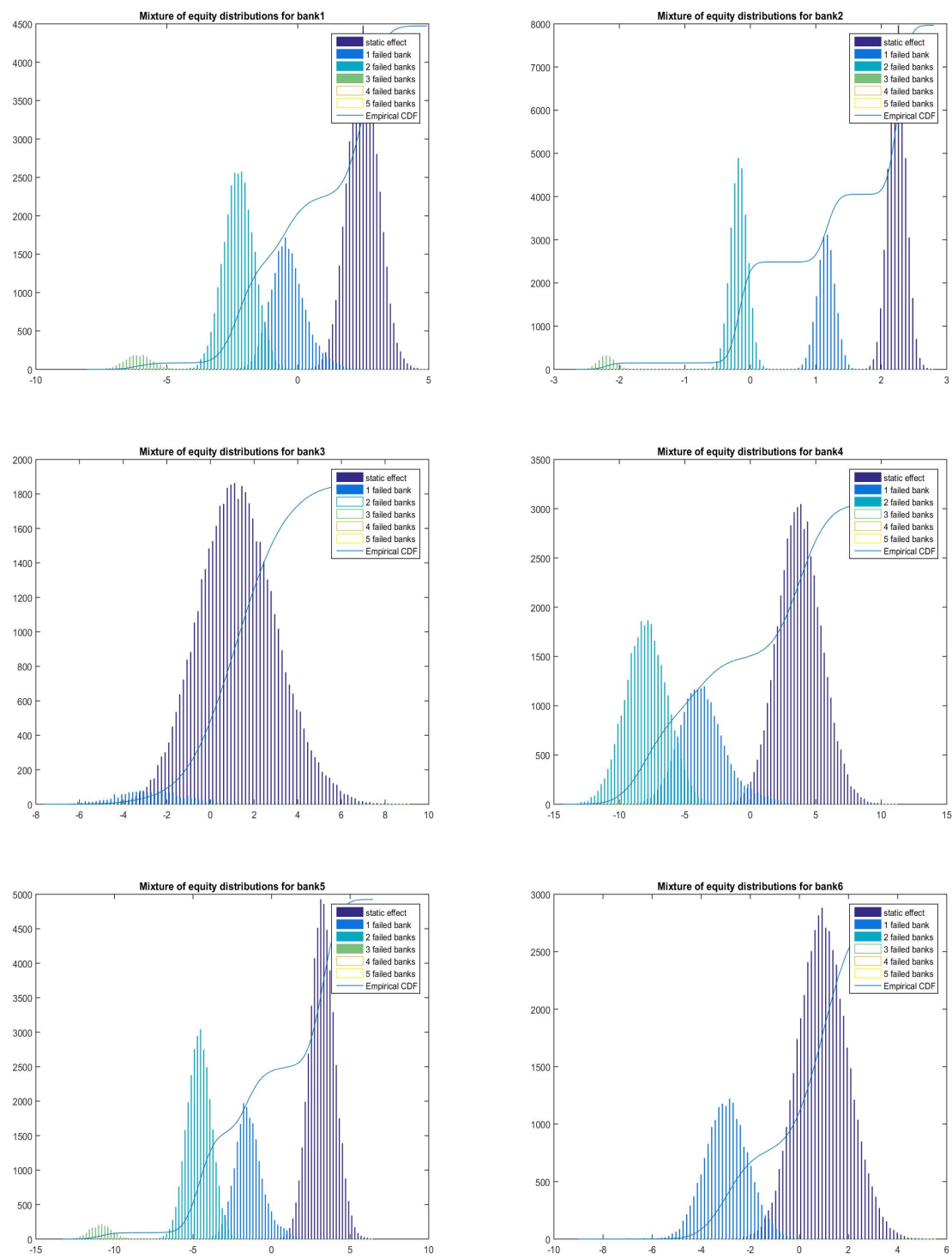

Figure 6: Partition of equity loss distribution at period 3.

Note: We consider equity distribution in period 3 as several modes tend to disappear in further periods as the size of the banking system reduces. Banks distribution of equity is divided according to the number of defaults in the previous period.

Equity distribution in figure 6 is split into 6 sub-distributions. The first one is called "direct effect". It presents the equity distribution conditional on no default of other institutions in the previous period ( 2 here). Then each distribution is the equity distribution of each bank conditional on the failure of respectively $\{1, \ldots, 5\}$ banks. Having split the distribution in such a way makes clear why multimodality appears in the system: the default of each bank is more probable as soon as other bank defaults. Therefore, the multimodality actually reflects, in our model, domino effects in the banking systems: an increasing number of defaults drags distributions toward smaller (negative) equity value. 
Banks 3 and 6 experiences are quite similar. As they are the most directly weakened by the initial shock, the majority of their distributions represent "direct effect" and the 1 bank failing mode. Other partitions have a small impact on the distribution: they contribute to create a significant tail risk such that second round effects appear relatively less strong. Bank 6 however is more exposed than its sibling 3 to the direct effect and is more likely to fail in period 3 subsequently to the default of 3 .

By contrast, banks $\{1,2,4,5\}$ equity distributions are multimodal in period 3 . To be precise, what could be interpreted at first sight as a bimodal distribution is mostly made of 4 distributions. We find again the same structure than bank 3 for the "direct effect" distributions. Then the contagion intensifies as soon as either bank 1 or 2 defaults in the previous period (distribution given two defaulting institutions on the left side): other banks can hardly survive. Note that bank 2 is a more resilient institution that is less hampered by the default of other banks in period 3 .

\subsection{The role of systemic banks}

As commonly defined, a systemic bank is a bank whom default could cause the bankruptcy of other institutions and threaten the entire financial system. This subsection shows how the model can be easily used to assess how systemic each bank is, taking into account second round effects. We use the model to create an artificial failure of one institution by constraining its equity to zero in the beginning of period 2, without setting any initial shock on asset prices. Defaults appears in period 3 and contagion spreads to other banks in the following periods. As our model is well suited to describe contagion effects among banks, the failure of a systemic credit institution is more likely to cause the failure of the entire network whereas the failure of a small institution causes less defaults. Probabilities of default and equity distributions are presented to characterize how systemic an institution is.

Let assumes banks 2 or 3 fail. Bank 2 is the smallest bank of the sample and shares few equity cross-holding with the rest of the network (see table 10). By contrast, bank 3 is the largest bank of the network. It is linked with every financial actor and the liquidation of its assets will highly impact the network's solvency. Figure 7 presents the evolution of probabilities of default for banks 2 and 3 failure, respectively in the left and right figures. 

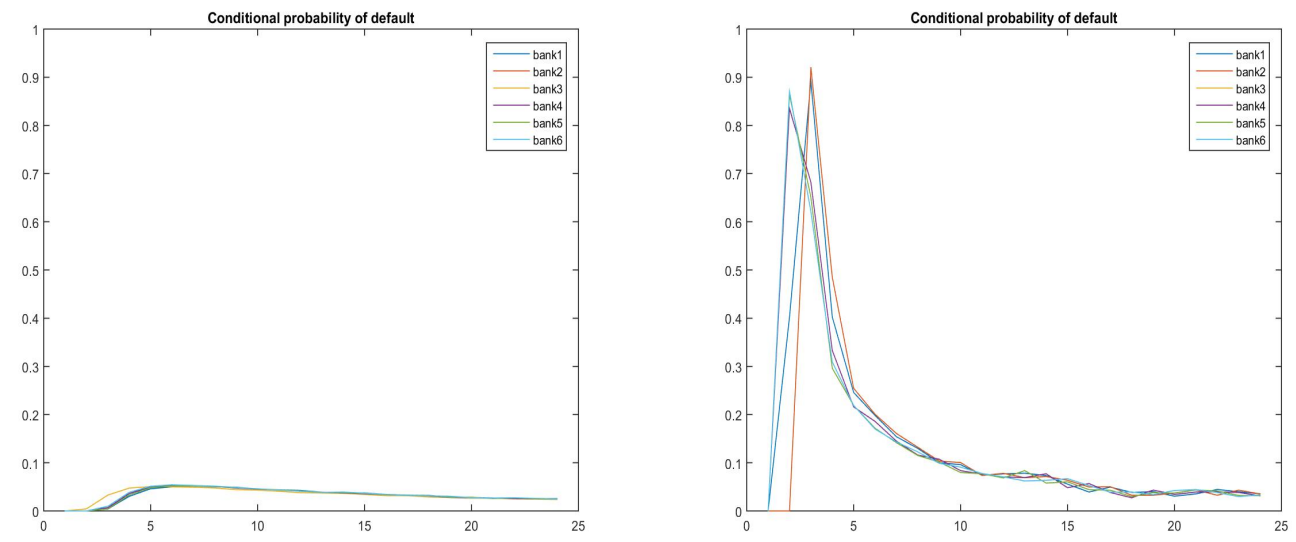

Figure 7: Banks PDs with the initial failure of a credit institution

Note: Banks PDs evolution are presented to observe the effect of a bank failure. Bank 2 fails in the left graph whereas bank 3 fails in the right figure.

They emphasize a strong difference between the two outcomes. Bank 3 failure increases dramatically the probabilities of default of the network. Banks 4, 5, and 6 have a probability of default of about 0.85 as a first round effect; banks 1 and 2 at 0.9 on the subsequent round. Because they share a few links with the rest of the network and has more equity, bank 1 and 2 are more resilient to the direct impact but very fragile as soon as more than a bank is in distress. These PDs are high and prove the systemicity of bank 3. Results are significantly different concerning bank 2 failure. It causes a slight increase of PDs but they are roughly ten times smaller than bank's 3 failure scenario. Banks 2 failure has a relatively small impact on the network's solvency and comes to be not a systemic institution. Therefore, probabilities of default evolution is a relevant indicator in order to highlight credit institutions systemicity in our model.

Equity losses distributions also provide insights on a bank's systemicity. As shocks on prices follow a Gaussian distribution at each period, equity loss distribution is likely to roughly follow a normal distribution if the failed bank is not systemic, whereas contagion effects may be observed for a systemic institution failure. Figures 8 and 9 present partitions of equity loss distributions after the failure of respectively banks 2 and 3 . 

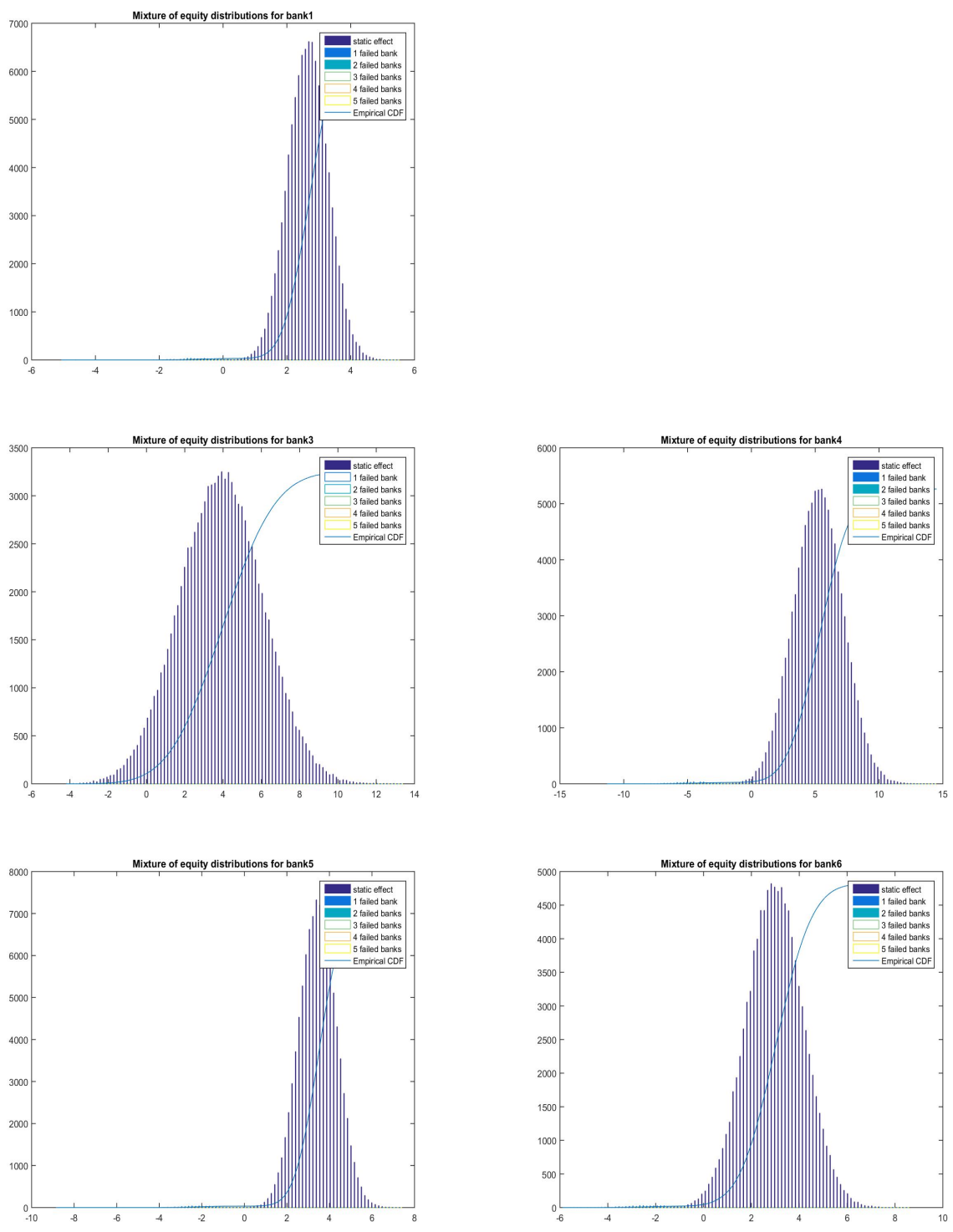

Figure 8: Partition of equity loss distribution at period 4 when bank 2 fails at period 2

Note: Equity distributions are still considered at period 4 so that they can be compared with benchmark distributions in figure 6 .

In line with the first insight provided by figure 7, we find that bank 2 is not a systemic institution. In fact, its failure does not trigger cascading defaults and surviving banks equity distributions are in line with Gaussian shocks on financial assets, as shown by the empirical cumulative distribution functions. Conditional distributions related to banks failure are secondary in front of the direct effect. 

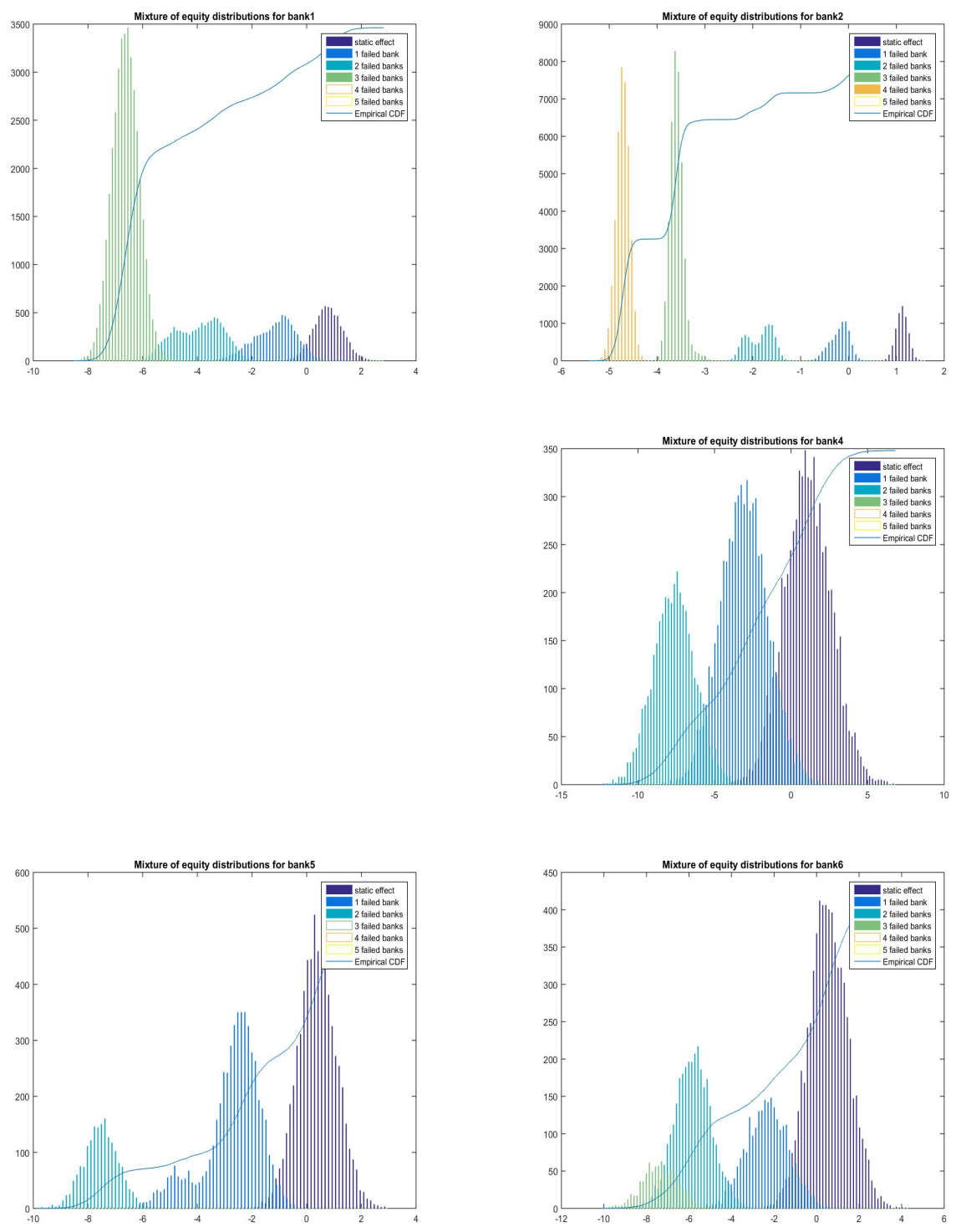

Figure 9: Partition of equity loss distribution at period 4 when bank 3 fails at period 2

Note: Equity distributions are still considered at period 4 so that they can be compared with benchmark distributions in figure 6 .

Figure 9 also supports the results from figure 7. Empirical cumulative distribution functions do not follow a Gaussian distribution. Besides, "direct effects" partition is lower than those of figure 8 . However it seems relatively important for banks $\{1,4,5\}$. It is explained by the high probability of default for these banks in period 3. 


\subsection{Systemic Contagion probability}

Previous simulations have emphasized how heterogeneous the consequences of a default are, depending on which bank is in distress. To capture this difference in systemicity, we derive a composite indicator aiming at measuring the impact of individual bank distress on the entire banking system. We propose a measure of systemicity that encompasses effects of direct losses, fire-sales and margin calls on the first and subsequent rounds. In our simulations, this indicator depends on the model calibration.

We define a Systemic Contagion probability for bank $i$ at round $t \mathcal{S C}_{i, t}$ as the expected impact of bank $i$ default on the system's default probability. $\mathcal{S C}_{i, t}$ measures the expected default probability of all possible combinations of banks in the system. The measure ranges from 0 to 1 , the latter corresponding to the failure of all remaining bank $\$^{3}$. Controlling with round $t$ allows us to analyze both the level of the Systemic Contagion and its propagation. Let's define

$$
\mathcal{S C}_{i, t}=\mathbb{E}\left(\sum_{\mathcal{B} \in \mathcal{P}(N \backslash\{i\})} \frac{\operatorname{card}(\mathcal{B})}{\operatorname{card}(\mathcal{N} \backslash\{i\})} \mathbb{P}\left(Y_{t}(\mathcal{B}) \leq 0, Y_{t}(\mathcal{N} \backslash\{i\} \backslash \mathcal{B})>0\right) \mid Y_{t=1}(i) \leq 0\right)
$$

$\mathcal{P}(N \backslash\{i\})$ is the set of partitions of all banks derived from the defaulted institution $i$. $\mathcal{B}$ therefore refers to a given partition in the set of all banks except the one $i$ we choose to default. The joint probability of having exactly the whole set $\mathcal{B}$ in default while the remaining institutions are not distressed is expressed by the probability $\mathbb{P}\left(Y_{t}(\mathcal{B} \leq 0), Y_{t}(\mathcal{N} \backslash\{i\} \backslash \mathcal{B})>0\right)$. $\operatorname{card}(\mathcal{N} \backslash\{i\})$ rescales the expected probability below 1 . This measure considers every partition of $\mathcal{N} \backslash\{i\}$ that corresponds to the set of banks that have defaulted before time $t$. We compute the expected probability for such event to happen and average them over the whole partitions of $\mathcal{N} \backslash\{i\}$ banks.

Unlike first results on default conditional probabilities in subsection 5.1, default probabilities are cumulative and unconditional on time.

\begin{tabular}{l|ccccc} 
& Round 2 & Round 3 & Round 4 & Round 5 & Round 6 \\
\hline Bank 1 & 0.02 & 0.10 & 0.21 & 0.30 & 0.37 \\
Bank 2 & 0.00 & 0.01 & 0.05 & 0.09 & 0.14 \\
Bank 3 & 0.59 & 0.94 & 0.96 & 0.97 & 0.98 \\
Bank 4 & 0.66 & 0.98 & 0.99 & 0.99 & 0.99 \\
Bank 5 & 0.14 & 0.40 & 0.53 & 0.61 & 0.67 \\
Bank 6 & 0.09 & 0.35 & 0.48 & 0.55 & 0.61
\end{tabular}

Table 15: Systemic Contagion $\mathcal{S C}_{i, t}$ of bank $i$ at time $t$, provided bank $i$ defaults at round 1.

This measure can also be adjusted for bank size. Indeed, the default of a few banks with large

\footnotetext{
${ }^{3}$ By definition, the Systemic Contagion probability tends to 1 as $t$ tends to infinity.
} 
exposures has more impact than default of several small institutions. We take into account the portfolio exposure of defaulting institutions in the next measure. The weighted Systemic Contagion evaluates the expected proportion of initial exposures in distress conditional on the failure of bank $i$.

$$
w \mathcal{S C}_{i, t}=\mathbb{E}\left(\sum_{\mathcal{B} \in \mathcal{P}(N \backslash\{i\})} \frac{\sum_{k \in \mathcal{B}} X_{t,\{1 \ldots, k\}} 1^{\prime}}{\sum_{k \in N \backslash\{i\}} X_{t, k} 1^{\prime}} \mathbb{P}\left(Y_{t}(\mathcal{B} \leq 0), Y_{t}(\mathcal{N} \backslash\{i\} \backslash \mathcal{B})>0\right) \mid Y_{t=1}(i) \leq 0\right)
$$

The latter uses the proportion of initial exposures $\frac{\sum_{k \in \mathcal{B}} X_{1,\{1 \ldots, k\}} 1^{\prime}}{\sum_{k \in N \backslash\{i\}} X_{1,\{1 \ldots, k\}} 1^{\prime}}$ from defaulted banks instead of counting the number of defaults. Numerical results are presented for each bank using the parameters from section 4.

\begin{tabular}{l|ccccc} 
& Round 1 & Round 2 & Round 3 & Round 4 & Round 5 \\
\hline Bank 1 & 0.03 & 0.13 & 0.23 & 0.32 & 0.38 \\
Bank 2 & 0.00 & 0.02 & 0.05 & 0.10 & 0.15 \\
Bank 3 & 0.75 & 0.95 & 0.97 & 0.97 & 0.98 \\
Bank 4 & 0.83 & 0.98 & 0.98 & 0.99 & 0.99 \\
Bank 5 & 0.21 & 0.43 & 0.54 & 0.62 & 0.67 \\
Bank 6 & 0.14 & 0.38 & 0.49 & 0.56 & 0.61
\end{tabular}

Table 16: Weighted Systemic Contagion $w \mathcal{S C}_{i, t}$ of bank $i$ at time $t$, provided bank $i$ defaults at round 1 .

The size of the defaulted institutions is a main determinant of the Systemic Contagion for both measures (weighted vs. non weighted): large banks are usually at the core of interbank trades and the size of their portfolio unleashes significant fire-sales. Still, weighted or not, banks with the largest measure of systemicity are not always the biggest ones.

Measures for banks 4 and 5 are respectively higher than those of banks 3 and 6 despite their smaller portfolios. Indeed, the Systemic Contagion measures the expected impact on the default of remaining institutions. It may be high for relatively smaller institutions because they are particularly connected to one big institution whom default in the second round on already weakened banks is more dangerous than the default of a bigger institution at a previous round (when other banks are not already fragile given the crisis).

\section{Disentangling the different channels of transmission}

As presented in section 3, the model highlights a complex framework in which it is analytically difficult to track over time the individual effects from each contagion channel. Decomposition between the three channels is possible for a single period. However, as soon as defaults occur, the subsequent downward shifts in prices and equity levels makes impossible to predict and 
thus disentangle the various effects from the three contagion channels. To overcome such difficulty, we conduct, in this section, simulations in which we shut down one contagion channel at a time to compare the results, and thus better assess the role of each contagion channel. For comparison purposes, we choose to use the conditional probability of default. The "benchmark" case is the one previously presented in Figure 4. In the several graphs of this section we present the "gain" in PDs obtained by "muting" one of the specified channel of transmission against the full model such that:

$$
\triangle P D=P D-\tilde{P D}
$$

where $P D$ is the probability of default of the full model and $\tilde{P D}$ is the probability of default of a partial model, i.e. when one of the transmission channel is muted.

\subsection{Neutralizing margin calls}

We prevent margin calls on the interbank market in this subsection. We consider banks do not have to compensate the loss in collateral value, such that there is no more asset price depreciations due to margin requirements. In other words, debtor-banks do not have to compensate creditor-bank for the loss in asset value. Two effects can be expected: (i) creditor-banks face higher credit risk since the implicit coverage of their lending is weakened but (ii) with no margin call debtor-banks do not have to sell assets, such that all banks may be better off since all (either creditor or debtor banks) are exposed in their balance-sheet to asset price risk. In our simulations, we observe that the probability of default for all banks is lower than in the benchmark case. Despite the fact that some of them directly loose from zero margin call, they indirectly avoid some risk of failure because fragile banks probability of default decreases, preventing the system from the risk of fire sales. 


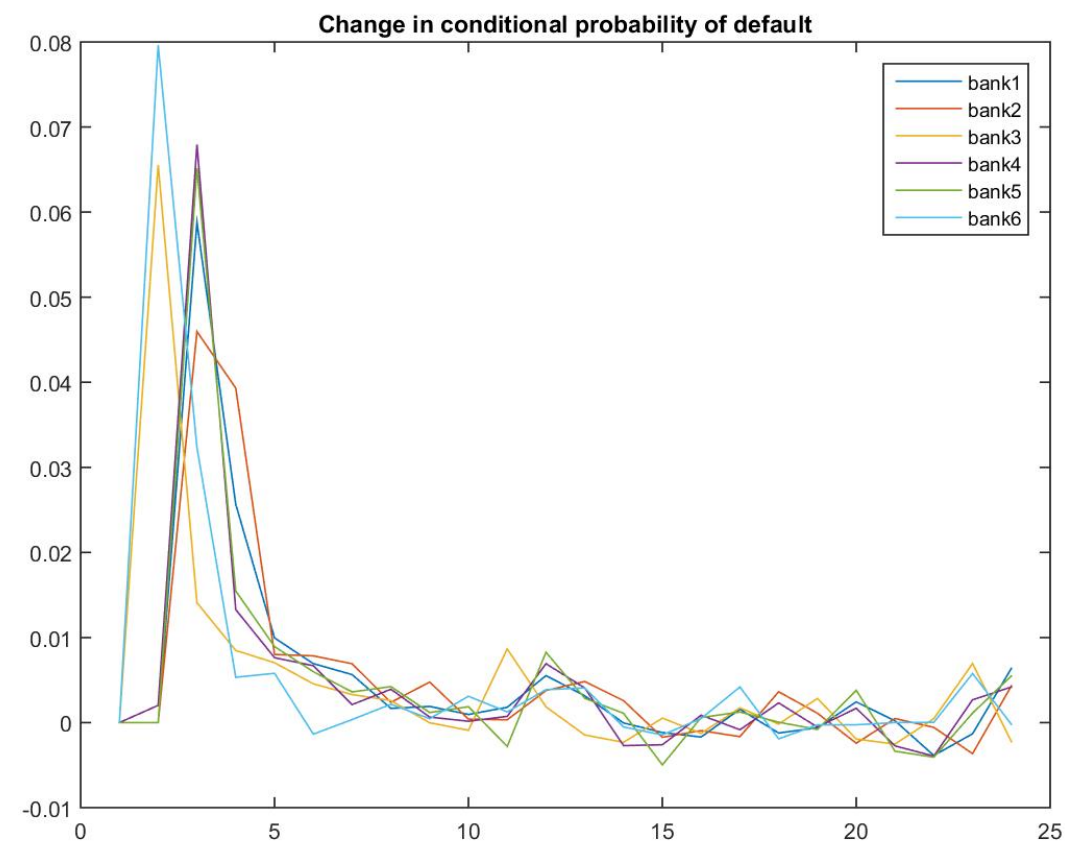

Figure 10: Gain in banks PDs when neutralizing margin calls.

Note: The gain in PDs reflects the difference between the PD of the full model against the PDs obtained by neutralizing margin calls in the simulation.

In this setup, as shown in Figure 10, all banks gain from removing margin calls, but debtor banks tend to benefit more than creditor banks.

\subsection{Neutralizing the fire-sales}

This subsection explores the outcome of neutralizing the effect of fire-sales on asset prices. To do so, we unrealistically consider the market to be deep enough to absorb banks' exposure without generating any price impact, such that the Amihud statistics is null. Compared to margin calls, there is no contradictory impact: the probability of defaults can only improve for all banks by two channels: for the creditor-banks, their portfolio does not depreciate, for debtor banks the impact is more neutral since it is the creditor-banks, once the margin-call occurs that bear the depreciation. Moreover, the failure of any institution does not erupt in a sharp decrease of prices. 


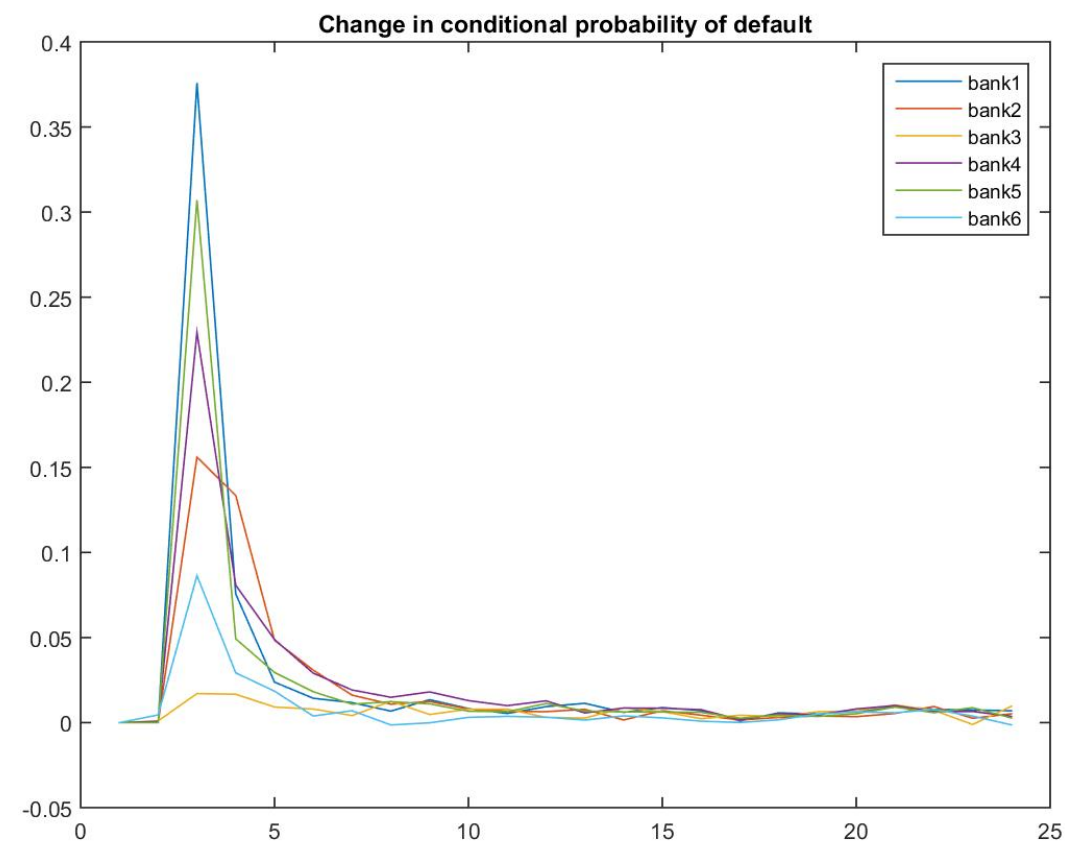

Figure 11: Gain in Banks PDs when quantities sold on the market has no impact anymore, i.e. no more fire-sales spirals.

Note: The gain in PDs reflects the difference between the PD of the full model against the PDs obtained if financial market liquidity is high enough to absorb without any discount the traded volumes by banks in the simulations.

As expected, Figure 11 shows that all banks, unambiguously, benefit from the absence of fire-sales. The gain is proportional to the exposure to market activities. The results allow us to assert that the asset prices impact overwhelmingly dominates other contagion channels. This calls for favoring high liquid assets when used as collateral in secured transaction.

\subsection{Considering an interbank market with no collateral}

This simulation evaluates the impact of unsecured instead of secured interbank loans. Two effects could be expected: (i) on the one hand, in the case of failure the creditor-bank suffers a complete loss of its exposure but (ii) on the other hand, there is no more direct link between the asset market and the interbank loans (as soon as there is no default). Moreover, if there is no collateral, there is no margin call mechanisms which makes debtor less prone to balance sheet contraction. 


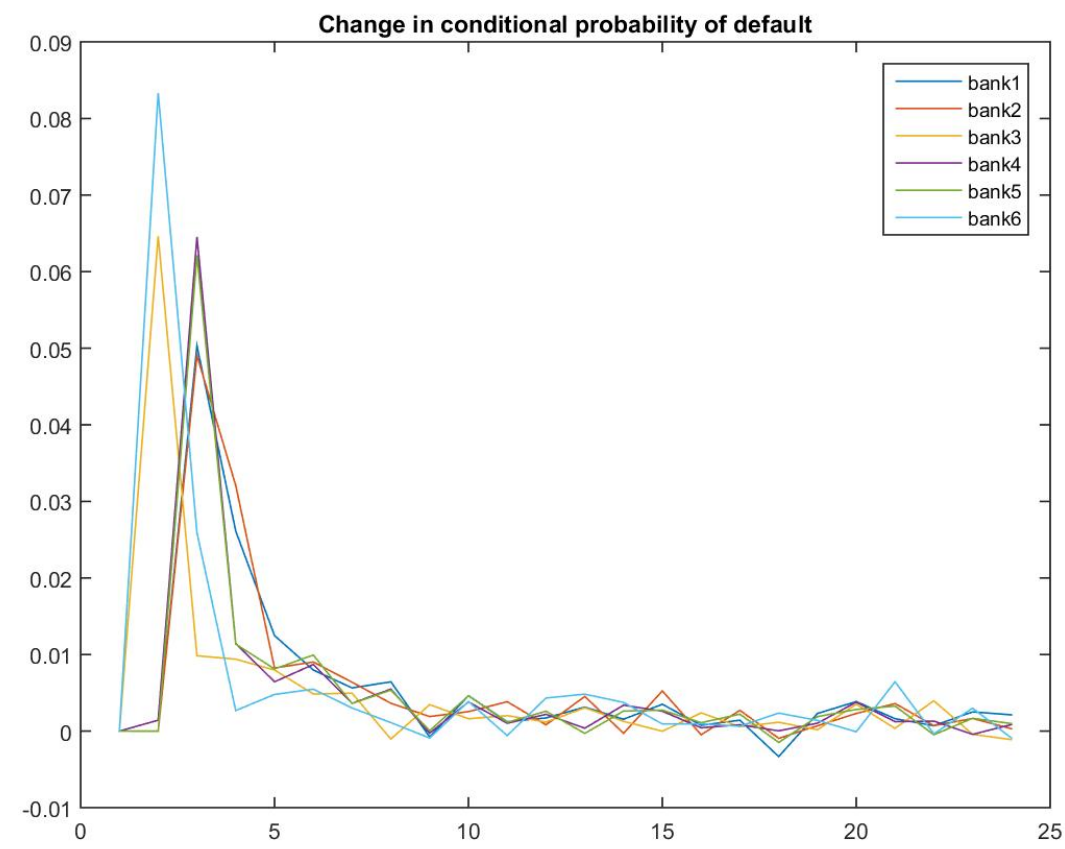

Figure 12: Banks PDs without collateral.

Note: The gain in PDs reflects the difference between the PD of the full model against the PDs obtained if the interbank is unsecured in the simulations.

Turning secured into unsecured loans decreases interbank contagion because no margin calls exacerbate banks' losses. The impact is similar to the one of margin calls. It means they amplify first round losses and failures in but the recovery from interbank loans is marginal as respect to the whole exposure of the bank.

\section{Conclusion}

We designed a network model to complement stress testing allowing for several channels of transmission, in an attempt to capture the complexity of the financial system characterized by distress transmission channels between banks, asset and interbank markets. We show that stress testing in a dynamic setting may trigger to an adverse situation in which the default of individual banks has a far higher probability to occur given second round losses. The model is flexible enough to account for many scenarios, both in terms of shocks and in terms of financial system features. The results of such simulations are very dependent on bank business models that constitute the system, namely their exposure to financial market, their reliance to interbank markets, or their exposure to other bank equities (e.g. by joint subsidiaries).

The advantage of such a framework is to give policy-makers an analysis of sensitivity of the banking system to shocks, that may not have a direct impact on bank balance sheets (for 
example the impact of market shocks on a bank with no market activity) but have second round effects when the shock propagates through the system due to financial contagion. We exploit our structural feature to derive a Systemic Contagion measure that may be useful to summarize in one composite indicator the systemic footprint of a bank in the network, and to track other time the spread of the pandemic. We have also tested for the optimal design of some policy actions aimed at neutralizing some channels of transmission in times of distress: in our simulations we have shown that it could be optimal, in order to limit defaults, to lower margin calls or to take action in such a way that only highly liquid and weakly correlated assets could be used as collateral for repo transactions.

Finally this framework offers many possibilities of adjustment to specific cases, institutions, financial systems to provide decision makers with a predicted impact of financial shocks. While limiting our network to 6 hypothetical banks so far, the model is flexible enough to consider a more complete panel of banks, which will give rise to non-trivial equity distributions once the system is affected by a shock. This would provide efficient and useful complement to standard stress-testing models that do not incorporate second round contagion effects. 


\section{References}

Acharya, V., R. Engle, and M. Richardson, 2012, A new approach to ranking and regulating systemic risks, The American Economic Review 102, 59-64.

Acharya, V., L. Pedersen, T. Philippon, and M. Richardson, 2010, Measuring systemic risk, Federal Reserve Bank of Cleveland Working paper, 1002.

Adrian, T., and M. K. Brunnermeier, 2011, Covar, NBER Working Paper 17454.

Adrian, T., and H.S. Shin, 2010, Liquidity and leverage, Journal of Financial Intermediation $19,418-437$.

Allen, F., and D. Gale, 2000, Financial contagion, The Journal of Political Economy 108, $1-33$.

Amihud, Y., 2002, Illiquidity and stock returns: cross-section and time-series effects, Journal of Financial Markets 5, 31-56.

Anand, K., I. van Lelyveld, . Banai, S. Friedrich, R. Garratt, G. Halaj, B. Howell, I. Hansen, S. Martnez Jaramillo, J. L. Lee, H. andMolina-Borboa, S. Nobili, S. Rajan, D. Salakhova, T. C. Silva, L. Silvestri, and S. R. Stancato de Souza, 2015, The missing links: a global study on uncovering financial network structure from partial data, mimeo.

Billio, M., M. Getmansky, A. Lo, and L. Pelizzon, 2012, Econometric measures of connectedness and systemic risk in the finance and insurance sectors, Journal of Financial Econometrics 104, 535-559.

Brownlees, C., and R. Engle, 2012, Volatility, correlation and tails for systemic risk measurement, Working Paper Series, Department of Finance, NYU.

Brunnermeier, M.K, and L.H. Pedersen, 2009, Market liquidity and funding liquidity, Review of financial studies 22, 2201-2238.

Brunnermeier, M. K., 2009, Deciphering the liquidity and credit crunch 2007-2008, The Journal of Economic Perspectives 23, 77-100.

Cifuentes, R., G. Ferrucci, and H. S. Shin, 2005, Liquidity risk and contagion, Journal of the Euroean Economic Association 3, 556-566.

Coval, J., and E. Stafford, 2007, Asset fire sales (and purchases) in equity markets, Journal of Financial Economics 86, 479-512.

Demange, G., 2012, Contagion in financial networks: A threat index, Paris School of Economics Working Paper 2012-02.

ECB, 2015, Euro money market study, 2014, .

Eisenberg, L., and T. H. Noe, 2001, Systemic risk in financial systems, Management Science 47, 236-249. 
Forbes, K., and R. Rigobon, 2001, No contagion, only interdependence: Measuring stock market co-movements, Journal of Finance 57, 2223-22261.

Gabrieli, S., D. Salakhova, and G. Vuillemey, 2015, Cross-border interbank contagion in the european banking sector, Banque de France Working paper 545.

Glasserman, P., and H. P. Young, 2015, How likely is contagion in financial networks?, Journal of Banking and Finance 50, 383-399.

Gourieroux, C., J.C. Heam, and A. Monfort, 2012, Bilateral exposures and sytemic solvency risk, Canadian Journal of Economics 45.

Greenwood, R., A. Landier, and D. Thesmar, 2015, Vulnerable banks, Journal of Financial Economics 115, 471-485.

Hollo, D., M. Kremer, and M. Lo Duca, 2012, CISS - a composite indicator of systemic stress in the financial system, ECB Working paper 1426.

Karolyi, A., 2003, Does international financial contagion really exist?, International Finance 6, 179-199.

Masson, P., 1999, Contagion: macroeconomic models with multiple equilibria, Journal of International Money and Finance 18, 587-602.

Merton, R., 1974, On the pricing of corporate debt : The risk structure of interest rates, Journal of Finance 29, 449-470.

Rodriguez, J. C., 2007, Measuring financial contagion: A copula approach, Journal of Empirical Finance 14, 401-423. 


\section{Documents de Travail}

603. C. Malgouyres, "The Impact of Chinese Import Competition on the Local Structure of Employment and Wages: Evidence from France" September 2016

604. G. Cette, J. Lopez and J. Mairesse, “Labour market regulations and capital labour substitution” October 2016

605. C. Hémet and C. Malgouyres, "Diversity and Employment Prospects: Neighbors Matter!” October 2016

606. M. Ben Salem and B. Castelletti-Font, "Which combination of fiscal and external imbalances to determine the longrun dynamics of sovereign bond yields?" November 2016

607. M. Joëts, V. Mignon and T. Razafindrabe, "Does the volatility of commodity prices reflect macroeconomic uncertainty?" November 2016

608. M. Bussière, G. Gaulier and W. Steingress, "Global Trade Flows: Revisiting the Exchange Rate Elasticities" November 2016

609. V.Coudert and J. Idier, “An Early Warning System for Macro-prudential Policy in France” November 2016

610. S. Guilloux-Nefussi, “Globalization, Market Structure and Inflation Dynamics” December 2016

611. S.Fries, J-S. Mésonnier, S. Mouabbi, and J-P. Renne, "National natural rates of interest and the single monetary policy in the Euro Area" December 2016

612. J. Blaum, C. Lelarge and M. Peters, “The Gains from Input Trade with Heterogeneous Importers” December 2016

613. A. Penalver, “Optimal Monitoring of Long-Term Loan Contracts” December 2016

614. M. Isoré and U. Szczerbowicz, "Disaster Risk and Preference Shifts in a New Keynesian Model” December 2016

615. L. Chauvet and L. Jacolin, "Financial Inclusion, Bank Concentration and Firm Performance” December 2016

616. P. A. Pintus, Y. Wen, and X. Xing, "The Inverted Leading Indicator Property and Redistribution Effect of the Interest Rate" December 2016

617. G. Cette, R. Lecat \& C. Ly-Marin, "Long-term growth and productivity projections in advanced countries" January 2017

618. V. Bignon and C. jobst, "Economic Crises and the Eligibility for the Lender of Last Resort: Evidence from 19th century France" January 2017

619. K. Istrefi and S. Mouabbi, "Subjective Interest Rate Uncertainty and the Macroeconomy: A Cross-country Analysis" January 2017

620. S. Avouyi-Dovi, C. Labonne, R. Lecat and S. Ray, "Insight from a Time-Varying VAR Model with Stochastic Volatility of the French Housing and Credit Markets" January 2017

621. J. Idier and T. Piquard, "Pandemic crises in financial systems: a simulation-model to complement stress-testing frameworks" January 2017

Pour accéder à la liste complète des Documents de Travail publiés par la Banque de France veuillez consulter le site : www.banque-france.fr

For a complete list of Working Papers published by the Banque de France, please visit the website: www.banque-france.fr

Pour tous commentaires ou demandes sur les Documents de Travail, contacter la bibliothèque de la Direction Générale des Études et des Relations Internationales à l'adresse suivante :

For any comment or enquiries on the Working Papers, contact the library of the Directorate General Economics and International Relations at the following address :

BANQUE DE FRANCE

49- 1404 Labolog

75049 Paris Cedex 01

tél : 0033 (0)1 42977724 ou 0142926340 ou 4890 ou 6981

email : 1404-ut@banque-france.fr 